\begin{abstract}
Title of Thesis:

EFFECTS OF DRIVERLESS VEHICLES ON THE COMPETITIVENESS OF BUS TRANSIT SERVICES

Shiyi Liu, Master of Science, 2019

Thesis Directed By: $\quad$ Professor, Paul M. Schonfeld, Department of Civil \& Environmental Engineering

The advent of driverless vehicles, including automobiles and buses, may considerably affect the competitiveness and ridership of public transportation services in negative as well as positive ways. Since driverless vehicles may be widely used in the fairly near future, public transit operators and transportation planners should prepare to deal with their anticipated effects. In this thesis the author (1) formulate modular optimization models for both human-driven and automated bus services with fixed routes as well as flexible routes, (2) develop preliminary quantitative assessments of those effects, showing that without drivers, competitiveness of public transportation compared to private transportation decreases; (3) conduct sensitivity analyses to explore how changes in input parameters affect the results; and (4) identify insights in which transit operators, transportation planners and other transportation system stakeholders may use in effectively adapting to the introduction of driverless vehicles.
\end{abstract}




\title{
EFFECTS OF DRIVERLESS VEHICLES ON THE COMPETITIVENESS OF BUS TRANSIT SERVICES
}

\author{
by
}

Shiyi Liu

\begin{abstract}
Thesis submitted to the Faculty of the Graduate School of the University of Maryland, College Park, in partial fulfillment of the requirements for the degree of Master of Science

2019
\end{abstract}

Advisory Committee:

Professor Paul M. Schonfeld, Chair

Professor Lei Zhang

Professor Cinzia Cirillo 
(C) Copyright by Shiyi Liu 2019 


\section{Acknowledgements}

Foremost, I would like to express my sincere gratitude to my advisor Prof. Paul Schonfeld for the continuous support of my master study and research, for his patience, motivation, enthusiasm, and immense knowledge. His guidance helped me in all the time of research and writing of this thesis. I could not have imagined having a better advisor and mentor for my master study.

Besides my advisor, I would like to thank the rest of my thesis committee: Prof. Lei Zhang and Prof. Cinzia Cirillo, for their encouragement, insightful comments, and hard questions.

I thank my fellow classmates in the university: Chenyang Fang, Shihan Lin, Bowen Li, Qianqian Sun, Cheng Feng, Sara and Mohammad for the sleepless nights we were working together before deadlines, and for all the fun we have had in the last two years. Also, I thank my friends from Tongji University: Tianyang Han, Jiarui Tan, Bowen Yang and Linjia He.

Last but not the least, I would like to thank my family: my parents Xiasheng Liu and Zhujing Li, for giving birth to me at the first place and supporting me spiritually throughout my life. I also want to express my appreciation for my girlfriend Haishan Zhang for her love and support throughout my graduate school career. 


\section{Table of Contents}

Acknowledgements ............................................................................................. ii

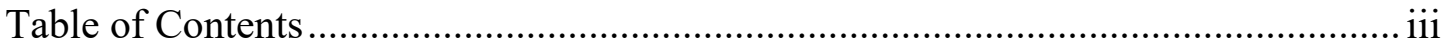

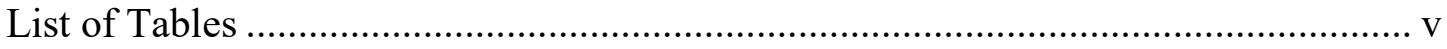

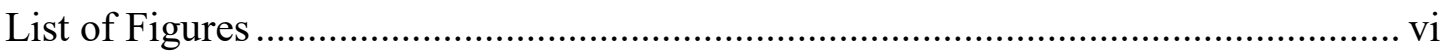

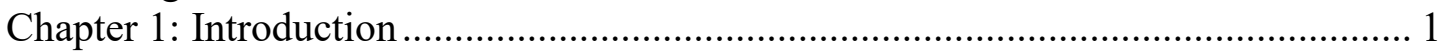

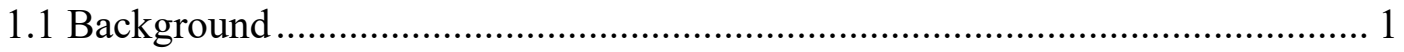

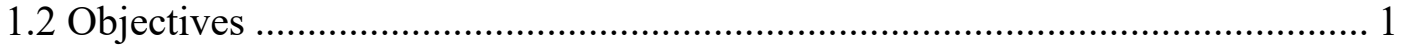

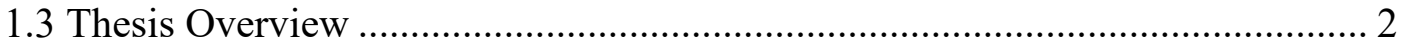

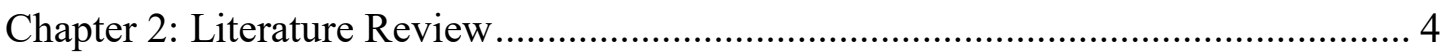

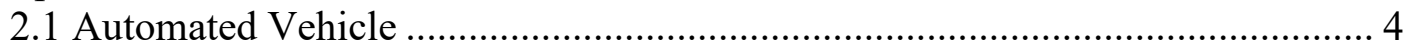

2.2 Analysis of Public Transportation Competitiveness ............................................ 7

2.3 Transit Service Optimization .................................................................... 9

2.4 Transit Service with Demand Elasticity .......................................................... 10

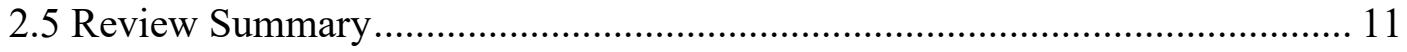

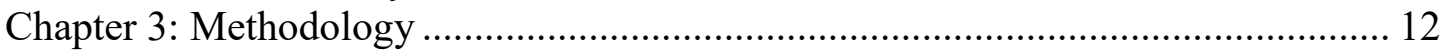

3.1 Problem Statement ……………………….......................................... 12

3.2 Notation and Assumption .......................................................................... 13

3.2.1 Notation and Baseline Value ............................................................... 13

3.2.2 Assumptions ..................................................................................... 15

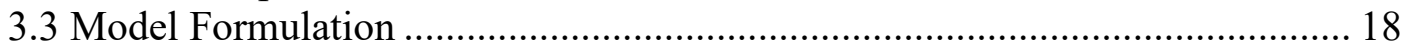

3.3.1 Automated Conventional Bus ............................................................... 18

3.3.2 Human-Driven Conventional Bus........................................................... 23

3.3.3 Automated Flexible Bus ..................................................................... 25

3.3.4 Human-Driven Flexible Bus ................................................................ 27

3.3.5 Automated and Human-Driven Private Car.............................................. 28

3.3.6 Human-driven Taxi ............................................................................. 31

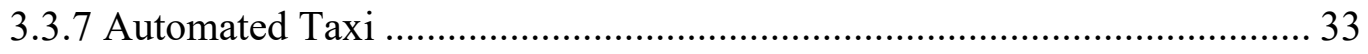

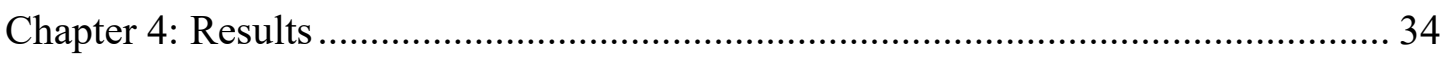

4.1 Problem Statement ................................................................................... 34

4.2 Summary of Optimization Results............................................................... 34

4.3 Formulation of Utility Functions …………………..................................... 37

Chapter 5: Sensitivity Analysis............................................................................. 41

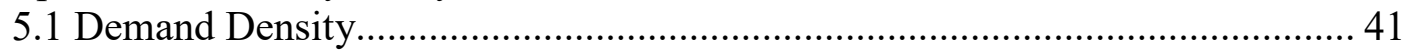

5.2 Market Penetration of Automated Vehicles................................................... 43

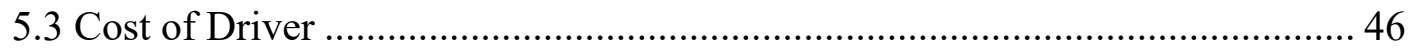

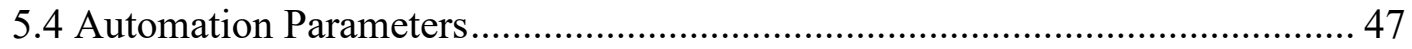

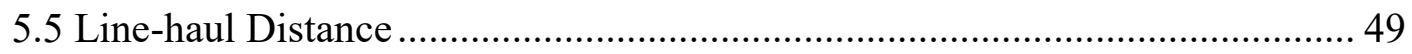

5.6 Expected Profit Margin Parameter...………………………........................... 51

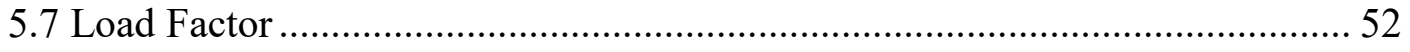

Chapter 6: Conclusions and Future Studies ............................................................. 54

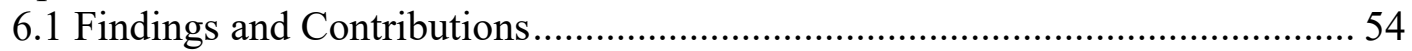




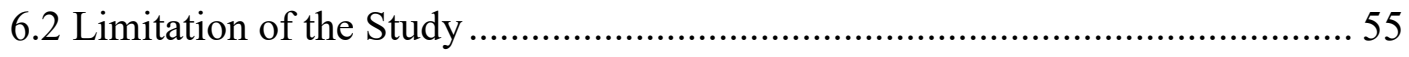

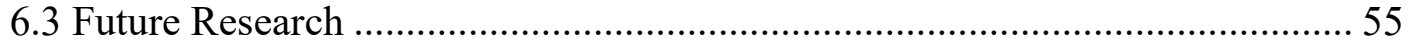

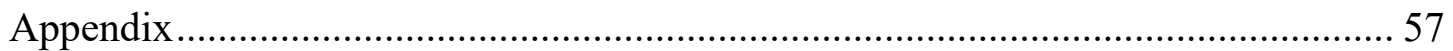

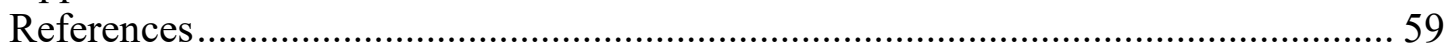




\section{List of Tables}

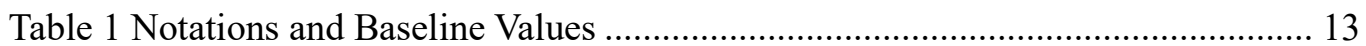

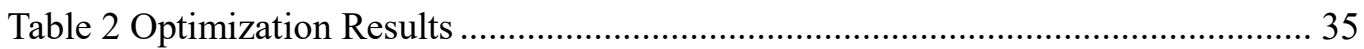

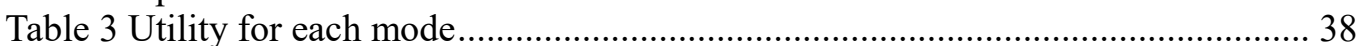

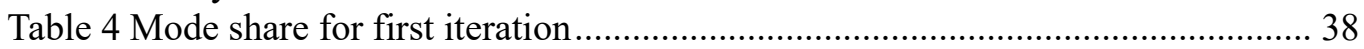

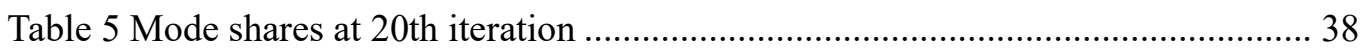

Table 6 Sensitivity analysis: optimized parameter with respect to load factor .............. 52 


\section{List of Figures}

Figure 1 Conventional and Flexible Bus Services ..................................................... 18

Figure 2 Cost comparison of different modes with and without autonomous vehicle

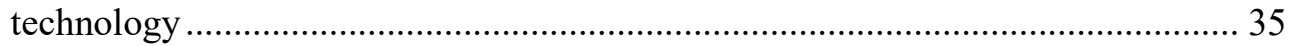

Figure 3 Sensitivity analysis: demand density and market share ............................... 42

Figure 4 Sensitivity analysis: AV Penetration and market share .................................. 44

Figure 5 Sensitivity analysis: AV Penetration and optimal bus size............................. 45

Figure 6 Sensitivity analysis: Cost of driver and market share ................................... 46

Figure 7 Sensitivity analysis: automation parameter and market share ........................ 47

Figure 8 Sensitivity analysis: line-haul distance and market share ............................. 49

Figure 9 Sensitivity analysis: profit margin coefficient for bus and market share......... 51 


\section{Chapter 1: Introduction}

\subsection{Background}

Public transport is a crucial service that supports human mobility. It may be considerably affected in performance, cost and service quality by the advent of automated vehicles (AV's). The major difference is the automated driving technologies can eliminate the cost of driver. Also, all else being equal, groups of AV's can move at a higher density for any given speed than "normal" human-driven vehicles, thereby increasing the service capacity of roads. Since the relevant hardware and software are improving faster than human drivers, AV's should eventually improve safety. Besides the advantages in capacity, speed and safety, people switching to automated private cars from human-driven ones may effectively decrease their cost of travel time as they can engage in non-driving activities. Quantitative analyses comparing automated and human-driven systems can be conducted through simulation modeling, cost-effectiveness analysis and other mathematical approaches. However, studies seem scarce on how AV technology would affect the competitiveness of public transport services.

\subsection{Objectives}

Specific objectives for this thesis are as follows:

1) Developing cost functions for different transportation modes. Developing analytic models to compare automated and human-driven conventional bus, 
flexible-route bus, private vehicle and taxi. Mathematical models are used to analytically optimize some characteristics for each alternative and to determine under what conditions, if any, is each alternative preferable. In formulating the total cost model for each bus service alternative, bus operating headway is treated as one of the optimizable decision variables. Other decision variables used here are bus size, route spacing for conventional bus service and service zone size for flexible-route bus services. In formulating the total cost model for each taxi service alternative, taxi fleet size is treated as an optimizable decision variable.

2) Develop a mode selection model for the minimal total cost. Demand functions with elasticity to service cost of each alternative should be formulated and applied to minimal mode choice problem. The objective functions for each transportation service are taken as the sum of user cost and operation cost. The mode selection model finds solutions for headways, fleet sizes, route spacings, service areas, and the market share of each alternative.

3) Conduct sensitivity analysis to explore how changes in demand density, operating cost, market penetration of automated vehicle, automation parameter will affect the relative competitiveness of bus transit service.

\subsection{Thesis Overview}

The rest of the thesis is organized as follows. Chapter 2 provides a literature review of research most closely related to this thesis, including perspectives on the impact of automated driving and transit service optimization. Chapter 3 develops formulations of the total cost function for the automated and human-driven 
conventional bus, flexible-route bus, private vehicle and taxi service. It begins by presenting assumptions about bus service, taxi service and service area. Then, these assumptions are translated in terms of user cost and operation cost. Chapter 4 demonstrates a logit mode choice model. Demand functions with elasticity to service cost of each alternative are formulated and applied to calculate the market share of each mode. Chapter 5 performs several sensitivity analyses for the optimal market share of each alternative acquired in chapter 4 , showing how changes in parameters affect these results. Finally, Chapter 6 draws conclusions from the thesis and suggests future directions for research. 


\section{Chapter 2: Literature Review}

This chapter reviews relevant studies on automated vehicle operations, transportation service optimization and demand elasticity in the analysis of bus transit services.

\subsection{Automated Vehicle}

Considerable research regarding automated driving has been conducted. In terms of purchase cost, Fagnant and Kockelman (2015) estimate that current AV's cost several times more than a conventional vehicle in the U.S. They estimate that this difference in cost could be gradually reduced to $\$ 3000$ or even less with mass production and technological advances in AV's. On the other hand, the introduction of AV's can also affect the users' time cost. In a stated preference survey in the Netherlands, Yap et al. (2016) find a higher value of time for using fully automated (level 5) compared to manually driven vehicles as an egress mode (i.e. train station to home) for train trips. This result violates the hypothesis that travel time disutility in an AV would be lower than in a human-driven car since travelers would be able to do other things instead of driving. According to their research, this result can be explained by the possible unease of travelers with the idea of riding in an AV due to lack of any real-life experience with such vehicles. Another explanation may be that the survey only treats AV's as the egress mode of train trips. An egress trip is short, so it does not allow travelers to fully experience the potential benefits of AV's, such as travel safety. Milakis et al. (2015) report a possible decrease of the value of time between $1 \%$ and $31 \%$ for users of AV's (level 3 and higher) in various scenarios of 
automated vehicle development in the Netherlands. Another important effect of AV's on traffic operation is increased road capacity. Ngoduy (2012) reports that a $30 \%$ penetration rate of automated cruise control (ACC) could significantly reduce oscillation waves and stabilize traffic near a bottleneck, thus reducing travel time by $35 \%$. Hoogendoorn et al. (2014) conclude in their review that automated driving might be able to reduce congestion by $50 \%$, and possibly even further with the help of vehicle-to-vehicle and vehicle-to-infrastructure communication. Shladover et al. (2012) show that as the penetration rate of Cooperative Adaptive Cruise Control (CACC) increases from $0 \%$ to $100 \%$, the capacity could theoretically double. Kamal et al. (2015) develop a control system which coordinates connected vehicles, so they can safely and smoothly cross an intersection with no traffic lights. Fagnant and Kockelman $(2014,2018)$ estimate that each shared AV could replace around 11 conventional vehicles. This rate drops to around 9 in a scenario with significantly increased peak hour demand. Chen et al. (2016) report that if vehicle charging is also taken into account in the case of shared electric AV's, then each shared AV may only replace 3.7 to 6.8 private-owned human-driven vehicles.

The introduction of AV's can also impact parking. Childress et al. (2015) identify potential changes in households' accessibility patterns in Seattle, WA, in a scenario where this region's transportation system is entirely based on AV's. This scenario not only assumes that driving is easier and more enjoyable (increasing capacity by $30 \%$ and the decreasing value of time by $35 \%$ ) but also cheaper due to lower parking costs. Zhang et al. (2015) and Spieser et al. (2014) offer estimates about a replacement rate of conventional vehicles by shared AV's that varies between 
3 and 14 . Thus, parking demand could be reduced from about $67 \%$ to over $90 \%$. Wu et al. (2011) demonstrate a fuel economy optimization system that provides human drivers or automated systems with advice about optimal acceleration and deceleration values, taking into account vehicle speed, acceleration, current speed limit, headway spacing, traffic lights and signs. Their driving simulator experiment of urban conditions with signalized intersections reveals a decrease in fuel consumption of up to $31 \%$ for drivers using the system. Fagnant and Kockelman's (2015) estimate for the cost of automation takes into account the safety, congestion, parking, travel demand and vehicle ownership impacts. It is based on several assumptions about market share, the number of AV's, fuel saving, delay reduction, crash reduction, and vehicle mile travel (VMT). Their results show that yearly social benefits such as lives saved and fewer crashes could reach $\$ 2960$ per AV (at 10\% market share) and increase up to $\$ 3900$ (at $90 \%$ market share) if the comprehensive costs of crashes are considered.

Speculation on how the introduction of fully autonomous vehicles will impact public transit varies among experts. Predictions range from a belief that shared AV fleets of personal-sized vehicles will effectively replace public transit, to a possibility of fleets of smaller autonomous buses, to an expectation that public transit will be strengthened by autonomous technology (Freemark, 2015). Eliminating or reducing mass public transit would be problematic, since replacing bus trips with personal vehicle trips would inevitably increase vehicle miles traveled, and therefore, congestion. Additionally, shared AVs may prove to be too expensive for many current bus users. With smaller fully autonomous buses, more vehicles would be needed to 
maintain current capacity. While this could be used to improve frequency, it may result in headway to be too small to maintain on some routes and will limit the ability of the routes to cope with any added demand. Additionally, a shift to more vehicles with lower occupancy could contribute to worsening congestion. Full size transit buses alleviate some of the concerns associated with smaller vehicles, by maintaining current capacity without a need to add vehicles. In fact, since the human drivers could be removed, it may be possible to make more capacity available for passengers. For these reasons, as well as ease of comparison, the autonomous technology portions of this thesis focus on the use of fully autonomous technology in full-size transit buses.

\subsection{Analysis of Public Transportation Competitiveness}

Travel mode refers to the choice of transportation mode by people or things during a trip, that is, the way people or things move from a point of origin to a destination. Public transportation has the merits of alleviating urban road congestion and is environmentally friendly. Guiding passengers to choose public transportation as their travel mode can be the key to solving urban traffic congestion. Thus, choices of travel mode and their influencing factors have long drawn the interest of researchers. Among them most of the researches are focusing on the attributes of the transit modes. Ma (2006) sums up all the influence factors associated with mode choice and regarded time, cost, comfort, and habit as the four essential factors. Xu et al. (2005) integrate various factors affecting residents' travel into six indicators which reflect the service level of urban passenger transportation (i.e., safety, economy, convenience, comfort, speed, and punctuality). They use these indicators as the fuzzy 
evaluation factors for the satisfaction rule model of residents' travel mode choice. Similarly, by analyzing origin-destination (OD) survey data from Bengbu city, Bao (2009) conclude that cost-saving, time-saving, and personal comfort are the primary considerations for residents' choice of travel mode. Focusing on commuting travel and shopping travel, Zhao (2008) analyze the influence of parking charges on travel mode choice using travel survey data of Beijing residents from 2005. The results show that parking charges greatly affected the mode choice after improvements in the public transit service level. In addition, reducing the number of non-commercial parking spaces and increasing the proportion of paid parking hours can also guide travelers to switch from private car travel to using public transit. Tyrinopoulos and Antoniou (2008) evaluate the influence factors leading to changes in passengerperceived satisfaction with the public transit using factor analysis and ordered logit modeling. They identify the most significant factors influencing passenger satisfaction in various traffic modes. Among them, quality of service and transfer quality appear to hold a top priority for the customers. These are associated with quality attributes comprised prices, information provision, waiting and in-vehicle conditions, accessibility and transfer coordination. Iseki and Taylor (2010) analyze users' experience at transit stops and stations and found that short walking time and reliable service matter most to riders' satisfaction. Habib et al. (2011) combine a multinomial logit model with latent variable models to capture factors that influence the choice of travel mode using data from a transit customer satisfaction survey, the results show that the most significant factors were reliability and convenience of public transit. Castillo and Benitez (2012) develop a framework based on the average 
model, multivariable discrete distribution model and generalized linear model to identify the relations between passengers' overall satisfaction and influence factors and quantify the impact degree of those factors on passengers' satisfaction. They conclude that public transit reliability is most influential in riders' perception of overall service quality. Ona et al. (2013) use structural equation modeling to reveal the relations between latent factors and overall service quality. They find that comfort and personnel behavior had little influence whereas those factors related to service had the highest weight overall service quality.

\section{$\underline{2.3 \text { Transit Service Optimization }}$}

Regarding transit service optimization, since Mohring's work (1972), many studies have optimized decision variables such as vehicle size, stop spacing and service areas for public transit services. In early studies by Newell (1979), Wirasinghe and Ghoneim (1981), Kocur and Hendrickson (1982), Tsao and Schonfeld (1983), Jansson (1980), Chang and Schonfeld (1991a,1991b,1993) and Chien and Schonfeld (1998), both network structure and demand pattern are greatly simplified to obtain closed-form solutions. Usually, the total cost objective, which includes both the suppliers' cost and users' cost, is minimized. After recent advances in computation power and optimization methods, studies are beginning to explore more realistic characteristics of public transit systems by relaxing some of these simplifying assumptions (e.g., uniform demand density throughout the study region). These studies assume a centralized optimization framework in which the single decision 
maker chooses either to minimize the total cost or to maximize total profit or social welfare, respectively, for private or public operators.

\subsection{Transit Service with Demand Elasticity}

In this section, papers of optimizing transit service with demand elasticity are reviewed. Kocur and Hendrickson (1982) optimize the decision variables namely route spacing, headway, and fare, with demand elasticity. They assume a linear transit utility function rather than a logit form. The reasons for the linear utility approximation are that it is analytically tractable, is easily differentiated and manipulated, and it is convex within its upper and lower bounds. They consider user waiting time, user access time, user in-vehicle time, fare, and time and cost of bus service in the demand model. They provide analytic closed form solutions, but this study is limited to a conventional bus service operating in a local region. Later, Imam (1998) extends Kocur and Hendrickson (1982)'s study by relaxing the linear demand function. In his work, a log-additive function is applied for demand.

Zhou et al (2008) formulate welfare for conventional bus services and flexible bus services, but only for a system connecting a terminal to one local region in one period. They find solutions analytically because the formulation of a system that connects a terminal to one local region in one period is analytically tractable. Analyses of system welfare with larger problem sizes (i.e., multiple regions and multiple periods) for both conventional and flexible services are desirable. They analyze tradeoffs between subsidies and welfare, but do not provide detailed enough methods to duplicate their results. Chien and Spasovic (2002) study a grid bus transit system with an elastic demand pattern. They optimize route spacings, station 
spacings, headways, and fare with the objective of maximum total operator profit and social welfare. The elastic demand is subtracted from the potential demand as in Chang and Schonfeld (1993), and the optimal solutions are found analytically. This work is applicable to conventional bus services.

Tsai et al (2013) find the headway and fare solutions for a Taiwan High-Speed Rail (THSR) line, with a maximum welfare objective. They consider elastic demand for the study and apply a genetic algorithm (GA) to obtain solutions. They compare solutions from a GA and solutions from an SSM (Successive Substitution Method). However, this study does not provide enough evidence on the global optimality of its solutions.

\section{$\underline{2.5 \text { Review Summary }}$}

In summary, the advent of AV's can considerably affect modern transportation systems. Also, many previous studies show that analytic optimization has various useful applications in optimizing public transportation system. To date, the impact of automated vehicle on bus transit service with joint optimization of their decision variables is largely neglected in the literature. It is necessary that such potential effects be identified and estimated quantitatively so that appropriate preparations, regulations and adjustments can be developed. In particular, for proper investment decisions for transportation infrastructure, especially in transit vehicles and facilities, effects of driverless vehicles on public transportation should be considered. 


\section{Chapter 3: Methodology}

\subsection{Problem Statement}

Automated vehicles are defined by the U.S. Department of Transportation's National Highway Traffic Safety Administration (NHTSA) as "those in which operation of the vehicle occurs without direct driver input to control the steering, acceleration, and braking and are designed so that the driver is not expected to constantly monitor the roadway while operating in self-driving mode.” They can provide a presumably safer, faster transit service. The potential impacts of integration of automated vehicle and bus transit have not been sufficiently explored. Those potential impacts are the subject of this chapter. In this thesis, eight transportation modes are modeled and compared, namely human-driven conventional bus (fixed route), human-driven flexible bus, human-driven private vehicle, human-driven taxi, automated conventional bus, automated flexible bus, automated private car and automated taxi. These are denoted, respectively as HC, HF, HP, HT, AC, AF AP and AT. Also, human-driven vehicles are denoted as HV and automated vehicles are denoted as AV. The modular geographic elements illustrated in Figure 1 serve manyto-1 (M-to-1) demand patterns, in which all users travel between a zone and a terminal. Many-to-many (M-to M) demand patterns can be served when multiple such elements are combined, and passengers transfer at a central terminal. This chapter modifies the cost function provided by Kim and Schonfeld (2014). More specifically, it (1) modifies the cost functions to reflect the impact of driver cost to relative 
competitiveness of each alternative, (2) develops models for taxi service and private vehicle and (3) compares human-driven and automated conventional bus, flexible bus, private vehicle and taxi under various assumed conditions. These models are intended for conceptual comparisons of services rather than detailed planning and operations.

\subsection{Notation and Assumption}

\subsubsection{Notation and Baseline Value}

Definitions and baseline values of variables are provided in Table 1, which are considered reasonably typical.

\section{Table 1 Notations and Baseline Values}

\begin{tabular}{|c|c|c|c|}
\hline Variable & Explanation & $\begin{array}{l}\text { Baseline value } \\
\text { (human-driven) }\end{array}$ & $\begin{array}{l}\text { Baseline value } \\
\text { (automated) }\end{array}$ \\
\hline $\mathrm{a}$ & fixed operating cost (\$/ vehicle hour) & 30 & 50 \\
\hline $\mathrm{b}$ & variable operating cost ( $\$$ / seat hour) & 0.2 & 0.45 \\
\hline $\mathrm{C}_{a}$ & $\begin{array}{l}\text { road capacity ratio with } \\
\text { proportion of } \mathrm{AV}\end{array}$ & 1 & 1.14 \\
\hline$C_{\text {fuel }}$ & private vehicle fuel cost (cent/mile) & 13.3 & 8.87 \\
\hline$C_{\text {main }}$ & $\begin{array}{l}\text { private vehicle maintenance cost } \\
\text { (cent/mile) }\end{array}$ & 4.256 & 24.24 \\
\hline$C_{\text {tire }}$ & private vehicle tire cost (cent/mile) & 1.2 & 1.2 \\
\hline$C_{D}$ & driver cost per hour ( $\$ /$ hour $)$ & 16 & 0 \\
\hline$C_{\text {depre }}$ & $\begin{array}{l}\text { private vehicle depreciation cost } \\
\text { (cent/mile) }\end{array}$ & 9.3 & 18.6 \\
\hline$C_{P}$ & $\begin{array}{l}\text { parking cost for private car per trip } \\
\text { (\$/trip) }\end{array}$ & 2 & 0 \\
\hline d & bus stop spacing (miles) & 0.2 & 0.2 \\
\hline $\begin{array}{l}\text { D } \\
\text { (conventional) }\end{array}$ & $\begin{array}{l}\text { equivalent average bus round trip } \\
\text { distance (mile) }\end{array}$ & 12.17 & 12.17 \\
\hline $\begin{array}{l}\text { D } \\
\text { (flexible) }\end{array}$ & $\begin{array}{l}\text { equivalent average bus round trip } \\
\text { distance (mile) }\end{array}$ & 4.5 & 4.5 \\
\hline $\mathrm{f}$ & market penetration of Automated & 0.5 & 0.5 \\
\hline
\end{tabular}


Vehicle

$\mathrm{F}$

$F_{t}$

$\mathrm{h}$

$\mathrm{J}$

$\mathrm{L}$

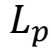

$\mathrm{m}$

M

$\mathrm{N}$

n

$\mathrm{p}$

Q

$\mathrm{u}$

$\mathrm{v}$

$\mathrm{V}_{C}$

$\mathrm{V}_{F}$

$V_{p}$

$V_{t}$

$V_{x}$

$\mathrm{W}$

W

$\mathrm{x}$

$\mathrm{y}$

Z

$\$_{F}$

$\$_{G}$

$v_{i}$

$v_{w}$

$\lambda$

$\mu$

$\phi$ fleet size (vehicles)

taxi fleet size (vehicles)

bus headway (hour)

Line haul distance of region(mile)

length of the service area(mile)

bus load factor

taxi and private car load factor

parameter for capacity function

equivalent average user trip distance

(mile)

number of branched zones in

conventional bus service

number of passengers in one flexible

bus tour

private car user value of time (\$/hour)

11.28

round trip demand density

(trips/ square mile $\cdot h r$ )

average number of people get on/off

each stop

value of user in vehicle time (\$/hour)

average speed of conventional bus

(mph)

25

average speed of flexible bus (mph)

average speed of private car (mph)

average speed of taxi (mph)

35

user access speed(mph)

width of the service area(mile)

2

3

value of user waiting time (\$/hour)

12

12

value of user access time (\$/hour)

express speed/local speed ratio for

conventional bus

Conv bus $=1.8$

Flex bus $=2.0$

Conv bus $=1.8$

Flex bus $=2.0$

same as $\mathrm{y}$

distance(\$/veh-mile)

taxi driver cost per vehicle hour $\$$ /veh-

h)

value of user in taxi time (\$/hour)

taxi value of user waiting cost(\$/hour)

20

taxi arrival rate

taxi service rate

price coefficient
14.1

40

40

1.2

1.2

5

4

28.6

20

35

40

40

2

3

9.6

9.6

same as y

0.28

0.32

17

0

15

12

16

.55

(2)

- -

1 1 


\begin{tabular}{llll}
$\theta$ & value of time reduction parameter & 1 & 0.8 \\
$\alpha$ (conventional bus) & expected profit margin & $10.5 \%$ & $10.5 \%$ \\
$\alpha$ (flexible bus) & expected profit margin & $10.5 \%$ & $10.5 \%$ \\
$\alpha$ (taxi) & expected profit margin & $21 \%$ & $21 \%$ \\
$\beta$ & payment transaction fee & 0.0044 & 0.0044 \\
VAT & value add-up tax & $5.5 \%$ & $5.5 \%$ \\
\hline
\end{tabular}

\subsubsection{Assumptions}

The following simplifying assumptions are made here for all eight modes:

- The service area is rectangular of length $\boldsymbol{L}$ and width $\boldsymbol{W}$. This area is connected with a transportation terminal at its nearest corner by a highway that is $\boldsymbol{J}$ miles long, as shown in Figure 1 .

- The demand is uniformly distributed over space within the region and uniformly distributed over the analyzed time period. Allowing the average waiting time of passengers to be approximated as half the headway.

- Bus layover time is negligible.

- The average speed of each mode includes stopping times.

- External costs are negligible.

- Movements in the service area are rectilinear.

The following assumptions are made only for the automated and human-driven conventional bus:

- The service area is divided into $\mathrm{N}$ branched zones uniformly with a route spacing of $\boldsymbol{r}=\boldsymbol{W} / \boldsymbol{N}$.

- In each round trip, buses travel from the terminal to a corner of the local regions on a highway with length $\boldsymbol{J}$ at non-stop speed $\boldsymbol{y} \boldsymbol{V}_{\boldsymbol{c}}$, then travel an 
average of $\boldsymbol{W} / \mathbf{2}$ miles at local non-stop speed $\boldsymbol{z} \boldsymbol{V}$ from the corner to the assigned zone, and then run a local route of length $\boldsymbol{L}$ at local speed $\boldsymbol{V}_{c}$ along the central axis of the zone while stopping for passengers every $\boldsymbol{d}$ miles, and then reverse the above process in returning to the terminal.

The following assumptions are made only for the automated and human-driven flexible bus:

- To simplify the flexible bus formulation, the service region of size $\boldsymbol{E}$ is divided into $\boldsymbol{N}$ equal zones, each having an optimizable zone area $\boldsymbol{A}=\boldsymbol{E} / \boldsymbol{N}$. Each zone should be fairly compact and convex.

- Buses travel from the terminal in a $\boldsymbol{J}$ length highway at non-stop speed $\boldsymbol{y} \boldsymbol{V}_{\boldsymbol{f}}$, and an average distance $(\boldsymbol{L}+\boldsymbol{W}) / 2$ miles at local non-stop speed $\boldsymbol{z} \boldsymbol{V}_{\boldsymbol{f}}$ to the center of each zone. They collect (or distribute) passengers at their doorsteps through an efficiently routed tour of length $\boldsymbol{D}$ with $n$ stops at local speed $\boldsymbol{V}_{\boldsymbol{f}}$. According to Stein (1978), D is approximated as $1.15 \sqrt{\boldsymbol{n A}}$ where $\boldsymbol{n}$ is the number of stops per flexible bus tour. Except when passengers travel in groups, $\boldsymbol{n}$ is also the sum of boarding and alighting passengers per tour. The values of $\boldsymbol{n}$ and $\boldsymbol{D}$ are endogenously determined. To return to their starting point the buses retrace an average of $(\boldsymbol{L}+\boldsymbol{W}) / 2$ miles at $\boldsymbol{z} \boldsymbol{V}_{\boldsymbol{f}}$ miles per hour and $\boldsymbol{J}$ miles at $\boldsymbol{y} \boldsymbol{V}_{f}$ miles per hour.

- Buses operate on schedules with optimized equal headways and with flexible routing designed to minimize each tour distance $\boldsymbol{D}$.

The following assumptions are made only for automated and human-driven private cars: 
- A private car travel route is partly similar to a flexible bus route. A private car travels from the terminal on a $\boldsymbol{J}$ length highway with at non-stop speed $\boldsymbol{V}_{\boldsymbol{p}}$, and then travel on the local road with an average distance $(\boldsymbol{L}+\boldsymbol{W}) / 2$ miles at local non-stop speed $\boldsymbol{V}_{\boldsymbol{p}}$. To return to its starting point a car retraces an average of $(\boldsymbol{L}+\boldsymbol{W}) / \mathbf{2}$ miles at $\boldsymbol{V}_{\boldsymbol{p}}$ miles per hour and $\boldsymbol{J}$ miles at $\boldsymbol{V}_{\boldsymbol{p}}$ miles per hour.

- The cost of automated private cars consists of depreciation, fuel consumption, tire expense, maintenance, repairs and user travel cost. The total cost for human-driven vehicles is first modeled, then its parameters are repaired with those for AV's.

The following assumptions are made only for automated and human-driven taxi:

- A taxi travel route is partly similar to a flexible bus route. A taxi picks up a passenger then travels from the terminal on a J length highway with at nonstop speed $V_{t}$, and then travel on the local road with an average distance (L + W)/2 miles at local non-stop speed $\boldsymbol{V}_{\boldsymbol{t}}$. Vehicle distance traveled between delivery trips are ignored. After picking up the passenger, the taxi returns to its starting point by retracing an average of $(\mathrm{L}+\mathrm{W}) / 2$ miles at $\mathrm{V}_{\mathrm{t}}$ miles per hour and $\mathrm{J}$ miles at $\mathrm{V}_{\mathrm{t}}$ miles per hour. 


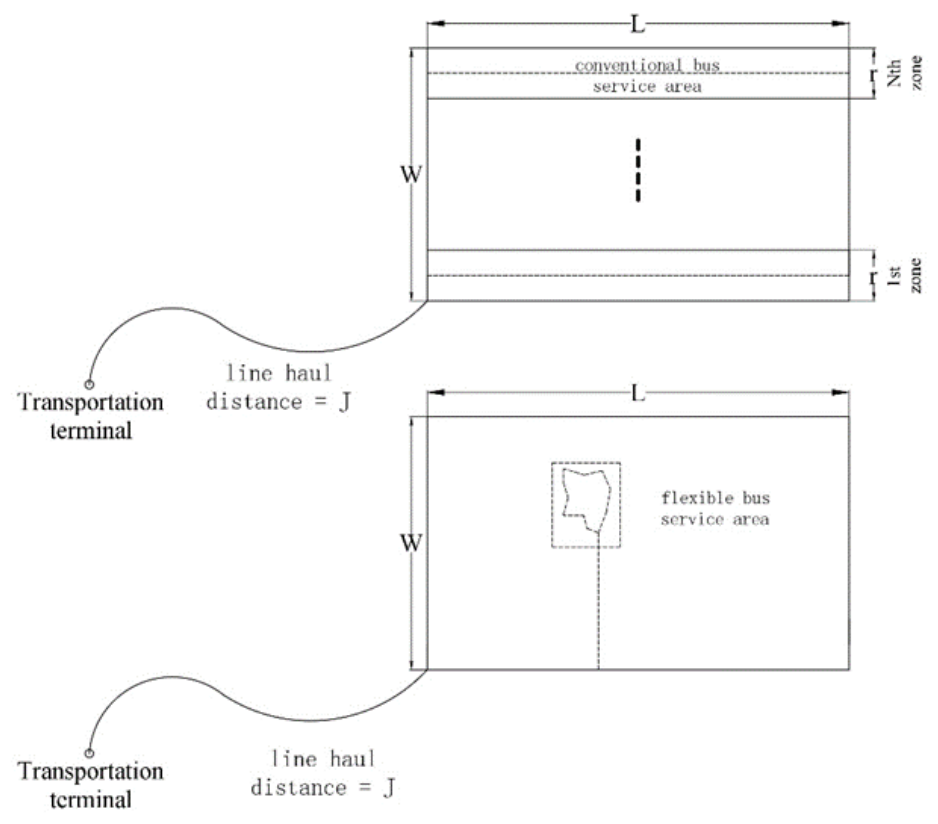

Figure 1 Conventional and Flexible Bus Services

\section{$\underline{3.3 \text { Model Formulation }}$}

For the operation cost of conventional and flexible bus, bus operating cost, user in-vehicle cost, user waiting cost and user access cost are considered. Since flexible bus provides door-to-door service, its user access cost is negligible. Detailed formulations regarding conventional bus and flexible bus, with baseline values, can be found in Kim and Schonfeld (2014).

\subsubsection{Automated Conventional Bus}

The effect of autonomous cars on the capacity of roads is considered in several studies. Zwaneveld and Van Arem (1997) review the early literature and argue that a doubling or tripling of capacity is likely. More recently, Shladover et al. (2012) find that the expected increase in capacity can be as low as $1 \%$ for autonomous cars that do not cooperate. However, Fernandes and Numes (2012) find that the increase 
can be as high as $414 \%$ with very efficient cooperation. The predicted capacity increases thus vary from almost no effect to a quintupling of capacity.

All results show that while switching from 100\% HV's to $100 \%$ AV's if vehicle types travel mixed, the capacity effect could be much less beneficial (e.g. Tientrakool et al. 2011). Van Arem et al. (2006) even found that introducing autonomous cars may reduce capacity when their share is low. Levin and Boyles (2016) found that the AV fraction must exceed $75 \%$ for capacity not to decrease due to inefficiencies with mixed traffic at intersections. These results show that the road capacity is a highly convex function of the share of AV's. The present analysis follows Van Den Berg and Verhoef's (2016) assumption that the capacity increases convexly with the penetration rate of AV's. They expressed the effect of market penetration of AV's on the structure of the capacity function as follows:

$$
\begin{gathered}
\mathrm{C}_{a}=\frac{C}{r[f]} \\
r[f]=1-0.5 \cdot f^{m}
\end{gathered}
$$

In Equation $1 \mathbf{C}_{\mathbf{a}}$ is the capacity with a fraction $\boldsymbol{f}$ of AV's on the road, $\boldsymbol{C}$ is the standard capacity. $\boldsymbol{m}$ is the parameter determining the convexity of the capacity function. When $\boldsymbol{m}$ is increasing, the capacity function is more convex. The baseline value is assumed to be $\boldsymbol{m}=2.0$ and thus the capacity function is highly convex. As stated earlier, the total demand here is assumed to be fixed. Hence, the relation between speed and market penetration of AV can be formulated as

$$
V_{c}^{a}=\frac{V_{c}^{h}}{\left(1-0.5 \cdot f^{m}\right)}
$$


Here $V_{c}^{a}$ and $V_{c}^{h}$ are the average speeds of, respectively, automated and humandriven conventional bus.

To determine operator costs, the fleet size $\mathrm{F}_{c}^{a}$ should be computed. It is found by dividing the total round-trip time by the headway and $\boldsymbol{D}$, which is the equivalent average bus round trip distance for the conventional bus.

$$
\begin{gathered}
\mathrm{D}=\frac{2 J}{y_{c}^{a}}+\frac{W}{z_{c}^{a}}+2 L \\
\mathrm{~F}_{c}^{a}=\frac{\mathrm{W}}{\mathrm{r}_{c}^{a}}\left(\frac{2 J}{y_{c}^{a} h_{c}^{a} V_{c}^{a}}+\frac{W}{z_{c}^{a} h_{c}^{a} V_{c}^{a}}+\frac{2 L}{h_{c}^{a} V_{c}^{a}}\right)=\frac{D W}{\mathrm{r}_{c}^{a} h_{c}^{a} V_{c}^{a}}
\end{gathered}
$$

The hourly operator costs $C_{o}$ are then the fleet size $\boldsymbol{F}$ multiplied by the operating cost $\boldsymbol{B}$ in $\$ /$ vehicle hour

$$
C_{o}=F B=\frac{2 J B}{y_{c}^{a} h_{c}^{a} V_{c}^{a}}+\frac{W B}{z_{c}^{a} h_{c}^{a} V_{c}^{a}}+\frac{2 L B}{h_{c}^{a} V_{c}^{a}}=\frac{B W D}{\mathrm{r}_{c}^{a} h_{c}^{a} V_{c}^{a}}
$$

The bus operating $\operatorname{cost} \boldsymbol{B}$ is formulated as

$$
\mathrm{B}=\mathrm{a}+C_{D}+\mathrm{bS}
$$

In Equation 3, $\boldsymbol{a}$ is the fixed cost including overhead and insurance. $\boldsymbol{b}$ denotes the variable cost including fuel cost, $\boldsymbol{C}_{\boldsymbol{D}}$ is the driver cost per hour and $\boldsymbol{S}$ is the vehicle size. For AV's, which have no driver cost, the operating cost is

$$
\mathrm{B}=\mathrm{a}+\mathrm{bS}
$$

The bus headway is formulated as

$$
h_{c}^{a}=\frac{\mathrm{S}_{c}^{a} L_{f}}{\mathrm{r}_{c}^{a} L Q}
$$

where $L_{f}$ is the bus load factor.

Equation 6 can be rewritten as 
$C_{o}=F B=\left(\frac{2 J}{y_{c}^{a} h_{c}^{a} V_{c}^{a}}+\frac{W}{z_{c}^{a} h_{c}^{a} V_{c}^{a}}+\frac{2 L}{h_{c}^{a} V_{c}^{a}}\right)\left(\mathrm{a}+\mathrm{bS}_{c}^{a}\right)=\frac{\left(\mathrm{a}+\mathrm{bS}_{c}^{a}\right) W D}{\mathrm{r}_{c}^{a} h_{c}^{a} V_{c}^{a}}=\frac{\left(\mathrm{a}+\mathrm{bS}_{c}^{a}\right) L W D Q}{L_{f} S_{c}^{a} V_{c}^{a}}$

The hourly user costs $\boldsymbol{C}_{\boldsymbol{u}}$ consist of in-vehicle cost $\boldsymbol{C} \boldsymbol{v}$, user waiting $\operatorname{cost} \boldsymbol{C w}$, and user access cost $\boldsymbol{C} \boldsymbol{x}$. When considering user cost, the difference in value of time (VOT) between human-driven and AV's should be considered. Here, a parameter $\boldsymbol{\theta}$ is used to express the driverless value of time: $\boldsymbol{v}_{a}=\boldsymbol{\theta} \boldsymbol{v}, \boldsymbol{w}_{\boldsymbol{a}}=\boldsymbol{\theta} \boldsymbol{w}, \boldsymbol{x}_{\boldsymbol{a}}=\boldsymbol{\theta} \boldsymbol{x}$.

The average user in-vehicle time is the average user travel distance divided by travel speed, and is formulated as

$$
\begin{gathered}
\mathrm{t}=\frac{J}{y_{c}^{a} V_{c}^{a}}+\frac{W}{2 z_{c}^{a} V_{c}^{a}}+\frac{L}{2 V_{c}^{a}}=\frac{M}{V_{c}^{a}} \\
M=\frac{J}{y_{c}^{a}}+\frac{W}{2 z_{c}^{a}}+\frac{L}{2}
\end{gathered}
$$

where $\mathbf{M}$ is the equivalent trip distance per user.

The user vehicle $\operatorname{cost} \boldsymbol{C v}$ is then

$$
C_{v}=v Q t=\frac{\theta v M L W Q}{V_{c}^{a}}
$$

where $\mathbf{Q}$ is the demand density.

Since the average wait time is assumed to be half the headway, the hourly user waiting cost is

$$
C_{w}=\frac{\theta w L W Q h_{c}^{a}}{2}=\frac{\theta w L W S_{c}^{a} L_{f}}{2}
$$

In Equation 14, w is the user value of waiting time per hour.

The user access cost is formulated as

$$
C_{x}=\frac{\theta x L W Q\left(\mathrm{r}_{c}^{a}+d\right)}{4 V_{x}}
$$

in which $\mathbf{x}$ is the user value of access time per hour, $V_{x}$ is the user access speed. 
To sum up, the total cost is formulated as

$$
\begin{gathered}
C_{c}^{a}=C_{o}+C_{w}+C_{x}+C_{v} \\
=\frac{\left(\mathrm{a}+\mathrm{bS}_{c}^{a}\right) L W D Q}{L_{f} \mathrm{~S}_{c}^{a} V_{c}^{a}}+\frac{\theta v M L W Q}{V_{c}^{a}}+\frac{\theta w W \mathrm{~S}_{c}^{a} L_{f}}{2 \mathrm{r}_{c}^{a}}+\frac{\theta x L W Q\left(\mathrm{r}_{c}^{a}+d\right)}{4 V_{x}}
\end{gathered}
$$

Here the vehicle size, bus headway and route spacing are optimized.

Simultaneously solving the derivatives of $C_{c}^{a}$ in Equation 17 with respect to route space $\mathrm{r}_{c}^{a}$ and vehicle size $\mathrm{S}_{c}^{a}$ reveals the optimal values of $\mathrm{r}_{c}^{a}$ and $\mathrm{S}_{c}^{a}$

$$
\begin{gathered}
\mathrm{r}_{c}^{a^{*}}=\left(\frac{8 w a D V_{x}^{2}}{\theta x^{2} L Q V_{c}^{a}}\right)^{\frac{1}{3}} \\
\mathrm{~S}_{c}^{a^{*}}=\left(\frac{8 L Q V_{x} a^{2} D^{2}}{x w \theta^{2} L_{f}^{3} V_{c}^{a^{2}}}\right)^{\frac{1}{3}}
\end{gathered}
$$

On the basis of optimized $\mathrm{r}_{c}^{a}$ and $\mathrm{S}_{c}^{a}$, the total cost can be formulated as

$$
C_{c}^{a}=\frac{\left(\mathrm{a}+\mathrm{bS}_{c}^{a^{*}}\right) W D}{\mathrm{r}_{c}^{a^{*}} V_{c}^{a} h_{c}^{a}}+\frac{\theta v M L W Q}{V_{c}^{a}}+\frac{\theta w L W Q h_{c}^{a}}{2}+\frac{\theta x L W Q\left(\mathrm{r}_{c}^{a^{*}}+d\right)}{4 V_{x}}
$$

The optimized headway can be obtained by setting the first derivative of $C_{c}^{a}$ to zero, Also, all the Hessian matrices are checked to be positive definite for all optimized relations in this thesis to ensure the results are globally optimal.

$$
h_{c}^{a^{*}}=\left(\frac{2\left(\mathrm{a}+\mathrm{bS}_{c}^{a^{*}}\right) D}{\theta w \mathrm{r}_{c}^{a^{*}} V_{c}^{a} L Q}\right)^{\frac{1}{2}}=\left(\left(\frac{a^{2} D^{2} x^{2}}{w^{4} V_{c}^{a^{2}} \theta^{2} L^{2} Q^{2} V_{x}^{2}}\right)^{\frac{1}{3}}+\left(\frac{8 D^{4} b^{3} a x}{w^{5} V_{c}^{a^{4}} \theta^{4} L_{f}^{3} L Q V_{x}}\right)^{\frac{1}{3}}\right)^{\frac{1}{2}}(20)
$$

The optimized headway should be the maximum allowable headway (for satisfying the demand) or the minimum cost headway, whichever is smaller. The maximum allowable headway is

$$
h_{c, \max }^{a}=\frac{\mathrm{S}_{c}^{a^{*}} L_{f}}{\mathrm{r}_{c}^{a^{*}} L Q}
$$


Thus, the optimal headway is then

$$
h_{c}^{a^{*}}=\min \left\{\frac{\mathrm{S}_{c}^{a^{*}} L_{f}}{\mathrm{r}_{c}^{a^{*}} L Q},\left(\frac{2\left(\mathrm{a}+\mathrm{bS}_{c}^{a^{*}}\right) D}{\theta w \mathrm{r}_{c}^{a^{*}} V_{c}^{a}}\right)^{\frac{1}{2}}\right\}
$$

The optimal fleet size $\mathrm{F}_{c}^{a}$ depends on the optimal headway

$$
\mathrm{F}_{c}^{a^{*}}=\frac{D W}{\mathrm{r}_{c}^{a^{*}} h_{c}^{a^{*}} V_{c}^{a}}
$$

The closed-form results in Equations 17 and 18 show how the optimal route spacing and bus size are related to exogenous characteristics. Basically, they have cubic root relations with system parameters. The optimal bus size is positively related to fixed operation cost, user access speed and round-trip distance. Also, it is negatively related to the automated VOT parameter, load factor and bus running speed. The optimal bus route spacing is negatively related to bus running speed and automated VOT parameter. These results indicate that when automated VOT parameter increase, a smaller bus size $\boldsymbol{S}$ and lower roundtrip time $\boldsymbol{r}$ are preferable. As shown in Equation 20, optimal bus headway is positively related to operation cost parameter and round-trip distance. Meanwhile, it is negatively related to automated VOT parameter. These results indicate that when automated VOT parameter increase, a smaller bus headway $\boldsymbol{h}$ is preferable.

\subsubsection{Human-Driven Conventional Bus}

The cost formulation for $\mathrm{HC}$ is similar to that for AC. The difference lies in driver cost and fixed and variable cost coefficient. The total cost for $\mathrm{HC}$ is formulated as follows: 


$$
\begin{gathered}
C_{c}^{h}=C_{o}+C_{w}+C_{x}+C_{v} \\
=\frac{\left(\mathrm{a}+C_{D}+\mathrm{bS}_{c}^{h}\right) L W D Q}{L_{f} \mathrm{~S}_{c}^{h} V_{c}^{h}}+\frac{v M L W Q}{V_{c}^{h}}+\frac{w W S_{c}^{h} L_{f}}{2 \mathrm{r}_{c}^{h}}+\frac{x L W Q\left(\mathrm{r}_{c}^{h}+d\right)}{4 V_{x}} \\
=\frac{\left(\mathrm{a}+C_{D}+\mathrm{bS}_{c}^{h^{*}}\right) W D}{\mathrm{r}_{c}^{h^{*}} V_{c}^{h} h_{c}^{h}}+\frac{v M L W Q}{V_{c}^{h}}+\frac{w L W Q h_{c}^{h}}{2}+\frac{x L W Q\left(\mathrm{r}_{c}^{h^{*}}+d\right)}{4 V_{x}}
\end{gathered}
$$

Similarly, the optimal vehicle size and route spacing can be expressed as follows,

$$
\begin{gathered}
\mathrm{r}_{c}^{h^{*}}=\left(\frac{8 w\left(\mathrm{a}+C_{D}\right) D V_{x}^{2}}{x^{2} L Q V_{c}^{h}}\right)^{\frac{1}{3}} \\
\mathrm{~S}_{c}^{h^{*}}=\left(\frac{8 L Q V_{x}\left(\mathrm{a}+C_{D}\right)^{2} D^{2}}{x w L_{f}{ }^{3} V_{c}^{h^{2}}}\right)^{\frac{1}{3}}
\end{gathered}
$$

The optimized headway can be formulated as,

$$
h_{c}^{h^{*}}=\left(\frac{2\left(\mathrm{a}+C_{D}+\mathrm{bS}_{c}^{h^{*}}\right) D}{w \mathrm{r}_{c}^{h^{*}} V_{c}^{h} L Q}\right)^{\frac{1}{2}}
$$

Thus, the optimal headway is then

$$
h_{c, o p t}^{h}=\min \left\{\frac{S_{c}^{h^{*}} L_{f}}{\mathrm{r}_{c}^{h^{*}} L Q},\left(\frac{2\left(\mathrm{a}+\mathrm{bS}_{c}^{h^{*}}\right) D}{w \mathrm{r}_{c}^{h^{*}} V_{c}^{h^{h}} L Q}\right)^{\frac{1}{2}}\right\}
$$

Equations 26 and 27 show how the optimal $\mathrm{HC}$ bus size and route spacing are determined by other system parameters. In comparing the optimal bus size and route spacing of human-driven and automated conventional bus systems in Equation 17 and 18. The most significant difference between $\mathrm{HC}$ and $\mathrm{AC}$ is the driver cost, as $\mathrm{AC}$ doesn't need a driver to operate the service. Although there is no driver cost for AC, 
the operation cost parameters $\boldsymbol{a}$ and $\boldsymbol{b}$ can presumably be greater for AC, so it cannot be decided which mode is more cost-effective based on Equations 17,18,26 and 27.

\subsubsection{Automated Flexible Bus}

Similarly, the total cost of flexible bus service consists of operating cost, user in-vehicle cost, and user waiting cost. However, since a flexible bus provides doorstep service, it has no user access cost, and the round-trip distance is different. The total cost is formulated as

$$
\begin{gathered}
V_{f}^{a}=\frac{V_{f}^{h}}{\left(1-0.5 \cdot f^{m}\right)} \\
\mathrm{D}_{f}=\frac{2 J}{y_{f}^{a}+\frac{L+W}{z_{f}^{a}}} \\
C_{f}^{a}=C_{o}+C_{w}+C_{v} \\
=\frac{L W}{A}\left(\frac{\mathrm{D}_{f}+1.15 A \sqrt{\frac{Q h}{u}}}{h V_{f}^{a}}\right)\left(\mathrm{a}+\mathrm{bS}_{f}\right)+\left(\frac{\mathrm{D}_{f}}{2 V_{f}^{a}}+\frac{1.15 A \sqrt{\frac{Q h}{u}}}{2 L W V_{f}^{a}}\right) \theta v L W Q+\frac{\theta w L W Q h}{2}
\end{gathered}
$$

Simultaneously solving the derivatives of $\boldsymbol{C}_{\boldsymbol{f}}^{\boldsymbol{a}}$ in Equation 32 with respect to service area $\mathbf{A}$ and vehicle size $\mathbf{S}$ yields the optimal values of $\mathbf{A}^{*}$ and $\mathbf{S}^{*}$,

$$
\begin{aligned}
\mathrm{S}_{f}^{a^{*}} & =\left(\frac{a^{3} u Q D^{3}}{1.15^{2} \theta w L_{f}^{3} V_{f}^{a}\left(b+\frac{\theta v L_{f}}{2}\right)^{2}}\right)^{\frac{1}{5}} \\
\mathrm{~A}_{f}^{a^{*}} & =\left(\frac{a(\theta w)^{3} V_{f}^{a 3} u^{\frac{8}{3}} D^{3} L_{f}^{4}}{1.15^{4} Q^{\frac{7}{3}}\left(Y^{a}\right)^{\frac{10}{3}}\left(b+\frac{\theta v L_{f}}{2}\right)^{2}}\right)^{\frac{1}{5}}
\end{aligned}
$$


In Equations 33 and 34, $\boldsymbol{Y}^{\boldsymbol{a}}$ is an intermediate variable and is specified as follows

$$
Y^{a}=\left(1.15^{2} a^{2} \theta w V_{f}^{a} L_{f}^{3}\right)^{\frac{1}{5}}+\left[u D^{3} Q\left(b+\frac{\theta v L_{f}}{2}\right)^{3}\right]^{\frac{1}{5}}
$$

The optimal flexible bus headway can be obtained with the following equation

$$
h_{f}^{a^{*}}=\frac{\mathrm{S}_{f}^{a^{*}} L_{f}}{\mathrm{~A}_{f}^{a^{*}} Q}=\left(\frac{1.15^{2} a^{2}\left(Y^{a}\right)^{\frac{10}{3}} f^{\frac{10}{3}}}{(\theta w)^{4} V_{f}^{a^{4}} u^{\frac{5}{3}} L_{f}^{2} Q^{\frac{5}{3}}}\right)^{\frac{1}{5}}
$$

The closed-form results in Equations 33, 34 and 36 show how the optimal bus size, area of service area and bus headway for flexible automated bus are related to exogenous characteristics. They have a complicated relation with other system parameters. The optimal headway is positively related to market penetration of AV and negatively related to $\theta$. The optimal service area is positively correlated with the $\theta$ and negatively correlated with the AV market penetration. These results indicate that bus headways and service areas decrease when the market penetration of AV's increase. Also, the change in headway and service area can be directly calculated from Equations 33, 34 and 36. Detailed elasticity will be shown in sensitivity analysis below.

Moreover, Equations 33, 34 and 36 show how the optimal vehicle size, zone area and headway are affected by other system parameters. In comparing the optimal headway of the AF system with that of the AC system in Equation 20, the following should be noted, 
(a) Some parameters which determine the conventional bus headway, such as the value of access time $\mathbf{x}$ and access speed $\boldsymbol{V}_{\boldsymbol{x}}$, do not affect the flexible bus headway, since the latter's passengers have doorstep service with no access distance.

(b) The relative effects on vehicle size of those parameters appearing in both Equation 20 and Equation 36 differ significantly. The optimal flexible-bus headway varies with the $4 / 5$ power of operating speed rather than the $2 / 3$ power of operating speed for conventional bus headway.

\subsubsection{Human-Driven Flexible Bus}

The formulation for HF is similar to that for automated flexible bus, but with some differences. First, AV's can eliminate the driver cost. Secondly, bus operating parameters such as $\boldsymbol{a}$ and $\boldsymbol{b}$ can be different. Thirdly, according to the literature, the user value of time can be different. The total cost for HF can be formulated as follows,

$$
\begin{gathered}
C_{f}^{h}=C_{o}+C_{v}+C_{w} \\
=\frac{L W}{A}\left(\frac{\mathrm{D}_{f}+1.15 A \sqrt{\frac{Q h}{u}}}{h V_{f}^{h}}\right)\left(\mathrm{a}+C_{D}+\mathrm{bS}_{f}\right) \\
+\left(\frac{\mathrm{D}_{f}}{2 V_{f}^{h}}+\frac{1.15 A \sqrt{\frac{Q h}{u}}}{2 L W V_{f}^{h}}\right) v L W Q+\frac{w L W Q h}{2}
\end{gathered}
$$

Similarly, for the HF, the total cost per trip can be optimized with respect to bus size and service area, 


$$
\begin{gathered}
\mathrm{S}_{f}^{h^{*}}=\left(\frac{a^{3} u Q D^{3}}{1.15^{2} w L_{f}^{3} V_{f}^{h}\left(b+\frac{v L_{f}}{2}\right)^{2}}\right)^{\frac{1}{5}} \\
\mathrm{~A}_{f}^{h^{*}}=\left(\frac{a w^{3} V_{f}^{h^{3}} u^{\frac{8}{3}} D^{3} L_{f}^{4}}{1.15^{4} Q^{\frac{7}{3}}\left(Y^{h}\right)^{\frac{10}{3}}\left(b+\frac{v L_{f}}{2}\right)^{2}}\right)^{\frac{1}{5}} \\
Y^{h}=\left(1.15^{2} a^{2} w V_{f}^{h} L_{f}^{3}\right)^{\frac{1}{5}}+\left[u D^{3} Q\left(b+\frac{v L_{f}}{2}\right)^{3}\right]^{\frac{1}{5}}
\end{gathered}
$$

Similarly, the optimal HF headway is

$$
h_{f}^{h^{*}}=\frac{\mathrm{S}_{f}^{h^{*}} L_{f}}{\mathrm{~A}_{f}^{h^{*}} Q}=\left(\frac{1.15^{2} a^{2}\left(Y^{h}\right)^{\frac{10}{3}}}{w^{4} V_{f}^{h^{4}} u^{\frac{5}{3}} L_{f}^{2} Q^{\frac{5}{3}}}\right)^{\frac{1}{5}}
$$

\subsubsection{Automated and Human-Driven Private Car}

The formulations of cost of automated private car and human-driven private are similar, the difference lies in parking cost, difference in travel speed and difference in parameter.

According to Barnes and Langworthy (2003), costs of AP include depreciation, fuel consumption, tire expense, maintenance, repairs and user travel cost. First, the total cost for regular HP is evaluated, and then the value of each parameter is adjusted based on effects of automated driving.

Fuel: the calculation of fuel cost is based on EPA (Environmental Protection Agency) fuel economy ratings, which estimate gallons needed per mile, multiplied by the fuel price. 
Maintenance: the cost of maintenance per mile is calculated by estimating five-year maintenance costs, excluding tires, and divided by the assumed 70000 miles. This per-mile cost is assumed to continue for the life of the vehicle.

Tires: the cost of tires per mile is calculated by estimating tire replacement cost divided by an assumed 45,000-mile tire life.

Repair: the cost of repair is calculated by estimating a five-year repair cost. The U.S. Department of Transportation (2017) indicates that generally half of these costs occur in the fifth year. Repair cost per mile is calculated as half of total repair cost divided by 56000 miles for the first four years and half of total repair cost divided by 14000 miles for the fifth year. The fifth-year cost is assumed to continue for the life of the vehicle. In estimating marginal repair costs, instead of considering the average age of all vehicles, the average age of the vehicles that are actually on the road at a given time is considered. This is almost certainly more weighted toward newer cars. It is assumed, based on registration patterns, that $1 / 3$ of all mileage is driven by cars that are less than five years old. Therefore, a weighted average for a vehicle's life can be obtained by multiplying the new-car repair cost by $1 / 3$ and the old-car cost by $2 / 3$.

Depreciation: N.A.D.A. (National Automobile Dealers Association) provides adjustment factors for used car prices based on mileage above and below the assumed average for a car of a given age. Other depreciation is assumed to be based on the age of the vehicle rather than mileage. Adjustment factors are given in four categories, mostly determined by the vehicle's initial value. The implied per-mile depreciation 
rate is higher for vehicles older than four years. A weighted average is computed similarly to repair costs.

The cost of the car is formulated as

$$
C_{c}=C_{\text {fuel }}+C_{\text {main }}+C_{\text {tire }}+C_{\text {depre }}
$$

On the other hand, the speed difference is still

$$
V_{p}^{a}=\frac{V_{p}^{h}}{\left(1-0.5 \cdot f^{m}\right)}
$$

User in-vehicle cost is calculated by multiplying user in vehicle value of time $p$ by travel time:

$$
C_{v}=p\left(\frac{L+W}{2 V_{p}}+\frac{J}{V_{p}}\right)
$$

The total cost is expressed in dollars per trip as follows:

$$
\begin{gathered}
C_{p}^{a}=C_{v}+C_{c}=\left(\frac{L+W}{2 L_{p}}+\frac{J}{L_{p}}\right)\left(C_{f u e l}^{a}+C_{\text {main }}^{a}+C_{\text {tire }}^{a}+C_{\text {depre }}^{a}\right) \\
+\theta p\left(\frac{L+W}{2 V_{p}^{a}}+\frac{J}{V_{p}^{a}}\right)
\end{gathered}
$$

where $L_{p}$ is the load factor of private car.

For HP, one difference is that parking cost should be included. AV's can drive themselves to an essentially free parking space or can be reused by other persons, as with taxis. Hence their parking cost can be assumed here to be negligible, unlike for HP, whose total cost would be

$$
\begin{aligned}
C_{p}^{h}=C_{v}+C_{P}+C_{c}= & \left(\frac{L+W}{2 L_{p}}+\frac{J}{L_{p}}\right)\left(C_{\text {fuel }}^{h}+C_{\text {main }}^{h}+C_{\text {tire }}^{h}+C_{\text {depre }}^{h}\right) \\
& +p\left(\frac{L+W}{2 V_{p}^{h}}+\frac{J}{V_{p}^{h}}\right)+\frac{C_{P}}{L_{p}}
\end{aligned}
$$




\subsubsection{Human-driven Taxi}

Cost of taxi service consists of user cost and operating cost. User cost consists of user in vehicle cost and user waiting cost. Operation cost consists of taxi running cost. First, the cost of human-driven taxi is formulated. The taxi fleet size is the decision variable to be optimized.

To begin with, the user in vehicle cost is formulated as value of user in vehicle time multiplies the average travel time. In the following equation $v_{i}$ denotes the value of user in vehicle time.

$$
C_{v}=v_{i}\left(\frac{L+W}{2 V_{t}^{h}}+\frac{J}{V_{t}^{h}}\right)
$$

Passenger waiting time can be approximately derived from queuing theory, by assuming that arrival rate $\lambda$ is average number of passengers per taxi, service rate $\boldsymbol{\mu}$ can be approximately estimated as $(\boldsymbol{1}-\boldsymbol{U} \boldsymbol{t}) \boldsymbol{F}$, where Ut is the average percentage of occupied taxis on the roads and $\boldsymbol{F}$ is the fleet size of taxi. Average taxi occupancy can be considered to be roughly proportional to the ratio of total occupied taxi time to total taxi service time.

$$
\begin{gathered}
U_{t}=\frac{L W Q\left(\frac{L+W}{2 V_{t}^{h}}+\frac{J}{V_{t}^{h}}\right)}{F_{t}^{h} L_{P}} \\
\lambda=\frac{L W Q}{L_{P} F_{t}^{h}} \\
\mu=\left(1-U_{t}\right) F_{t}^{h}
\end{gathered}
$$

Under standard $\mathrm{M} / \mathrm{M} / 1$ queuing regime, the average waiting time in the system is $\boldsymbol{t}_{W}=1 /(\boldsymbol{\mu}-\lambda)$ where $\boldsymbol{t}_{W}$ is the expected waiting time and $\boldsymbol{\mu}$ and $\lambda$ are service and arrival rates, respectively. 
Taxi operation cost depends on vehicle-distance per hour of operation, $\boldsymbol{G}$, and the fleet size, $\boldsymbol{F}$. Any vehicle distance traveled between delivery trips (e.g., the distance traveled to pick up the next passenger) is ignored, hence

$$
\mathrm{G}=\mathrm{LWQ}\left(\frac{L+W}{2}+\mathrm{J}\right)
$$

The author follows the method used by Nourbakhsh and Ouyang (2011), which converts the travel time and distance equivalents into dollars. Suppose $\$_{G}^{h}$ (\$/veh-mile) is the agency operation cost per vehicle-distance, $\$_{\mathrm{F}}(\$ /$ veh-h) is the agency cost per vehicle hour, and $v$ is the average monetary value of one passengerhour. $\$_{G}^{h}$ and $\$_{\mathrm{F}}$ are the operating cost relate to distance and time, respectively. $\$_{G}^{h}$ include cost of depreciation, fuel consumption, tire expense, maintenance, repairs. $\$_{\mathrm{M}}$ include the cost of driver and parking. However, the parking cost is negligible for taxi service. $v_{i}$ is user in vehicle value of time and $v_{w}$ is user waiting value of time. Thus, the cost of human-driven taxi can be formulated as,

$$
\begin{gathered}
C_{t}^{h}=C_{v}+C_{w}+C_{O} \\
=v_{i}\left(\frac{L+W}{2 V_{t}^{h}}+\frac{J}{V_{t}^{h}}\right)+\frac{2 v_{w} V_{t}^{h} F_{t}^{h}}{2 V_{t}^{h} F_{t}^{h^{2}}-L W Q F_{t}^{h}(L+W+2 J)-2 L W Q V_{t}^{h}} \\
+\frac{\$ G F_{t}^{h} L_{P}}{L W Q}\left(\frac{L+W}{2}+\mathrm{J}\right)+\frac{\$ F F_{t}^{h} L_{P}}{L W Q V_{t}^{h}}\left(\frac{L+W}{2}+\mathrm{J}\right)
\end{gathered}
$$

The minimum cost fleet size can be obtained by setting the partial derivatives with respect to fleet size to zero.

$$
\frac{\partial C_{t}^{h}}{\partial F_{t}^{h}}=\frac{v_{w}\left(F_{t}^{h^{2}}-\frac{L W Q M F_{t}^{h}}{V_{t}^{h}}-L W Q\right)-v_{w}\left(2 F_{t}^{h}-\frac{L W Q M}{V_{t}^{h}}\right) F_{t}^{h}}{\left(F_{t}^{h^{2}}-\frac{L W Q M F_{t}^{h}}{V_{t}^{h}}-L W Q\right)^{2}}+\left(\pi_{G}^{h}+\frac{\pi_{F}}{V_{t}^{h}}\right) \frac{M L_{P}}{F_{t}^{h}}=0(
$$

where 


$$
\pi_{G}^{h}=\frac{\$_{G}^{h} F_{t}^{h}}{L W Q}, \pi_{F}=\frac{\$_{F} F_{t}^{h}}{L W Q}, M=\left(\frac{L+W}{2}+\mathrm{J}\right) \text { and } F_{t}^{h}=\text { integer }
$$

Equation 53 is a quartic equation with respect to fleet size. Optimized fleet size is denoted as $F_{h t}^{o p t}$. The solution to Equation 53 is presented in the Appendix. Only one of the four solutions to this equation is feasible. The integer constraint is required to obtain integer values for the number of taxis. To obtain total cost with integer solutions, the decision variables are first to be optimized, and then compare their neighboring integer solutions to satisfy such constraints. Also, we check that all the Hessian matrices are positive definite for all optimized relations in this thesis to ensure the results are globally optimal.

\subsubsection{Automated Taxi}

The formulation of cost of automated taxi is similar to human-driven taxi, while the difference lies in agency operation cost per vehicle-distance, driver cost, and travel speed. For automated taxi, the driver cost is negligible. The speed difference is the same as for bus

$$
V_{t}^{a}=\frac{V_{t}^{h}}{\left(1-0.5 \cdot f^{m}\right)}
$$

Therefore, the cost for automated taxi can be formulated as

$$
\begin{gathered}
v_{i} \theta\left(\frac{L+W}{2 V_{t}^{a}}+\frac{J}{V_{t}^{a}}\right)+\frac{C_{v}+C_{w}+C_{O}}{2 V_{t}^{a} F_{t}^{a^{2}}-L W Q F_{t}^{a}(L+W+2 J)-2 L W Q V_{t}^{a}} \\
+\frac{\$_{G}^{a} F_{t}^{a} L_{P}}{L W Q}\left(\frac{L+W}{2}+\mathrm{J}\right)
\end{gathered}
$$

The minimum cost fleet size can also be obtained by setting the partial derivatives with respect to fleet size to zero. 


$$
\frac{\partial C_{t}^{a}}{\partial F_{t}^{a}}=\frac{v_{w}\left(F_{t}^{a}{ }^{2}-\frac{L W Q M F_{t}^{a}}{V_{t}^{a}}-L W Q\right)-v_{w}\left(2 F_{t}^{a}-\frac{L W Q M}{V_{t}^{a}}\right) F_{t}^{a}}{\left(F_{t}^{h^{a}}-\frac{L W Q M F_{t}^{a}}{V_{t}^{a}}-L W Q\right)^{2}}+\pi_{G}^{a} \frac{M L_{P}}{F_{t}^{a}}=0(57)
$$

where

$$
\pi_{G}^{a}=\frac{\$_{G}^{a} F_{t}^{a}}{L W Q}, M=\left(\frac{L+W}{2}+\mathrm{J}\right) \text { and } F_{t}^{a}=\text { integer }
$$

\section{Chapter 4: Results}

Numerical studies are conducted to compare the competitiveness of various models. The baseline parameter values are specified in Table 1, the assumed baseline for configurations of service area and bus services are suggested by previous studies (e.g. Kim and Schonfeld 2014), the value of time baselines are recommended values by the U.S. Department of Transportation (2017).

\subsection{Problem Statement}

Transit riders may have different service preferences based on fares, travel times, and other factors. In this chapter, different service qualities and demand elasticities are considered in user making choices from all eight modes. Total cost minimization is not a reasonable objective when the demand is elastic, since the demand can be driven toward zero when minimizing costs. Instead of minimizing total system cost, the objective in this chapter is to quantify the relative competitiveness of each transportation mode.

\subsection{Summary of Optimization Results}

Table 2 presents optimization results for each model in terms of average cost per trip. 
Table 2 Optimization Results

\begin{tabular}{|c|c|c|c|}
\hline variable & explanation & $\begin{array}{l}\text { baseline value } \\
\text { (human-driven) }\end{array}$ & $\begin{array}{l}\text { baseline value } \\
\text { (automated) }\end{array}$ \\
\hline $\mathrm{S}^{*}$ (flexible) & optimal flexible bus size(seats/bus) & 15.88 & 20.42 \\
\hline$A^{*}$ & $\begin{array}{l}\text { optimal flexible bus service area } \\
\text { (square mile) }\end{array}$ & 2.91 & 4.14 \\
\hline Y & parameter & 29.97 & 33.26 \\
\hline $\mathrm{S} *($ fix route $)$ & $\begin{array}{l}\text { optimal conventional bus } \\
\text { size(seats/bus) }\end{array}$ & 22.34 & 17.26 \\
\hline $\mathrm{h} *$ (flexible) & optimal flexible bus headway (hr) & 0.14 & 0.12 \\
\hline $\mathrm{h} *($ fix route $)$ & optimal fix route bus headway (hr) & 0.17 & 0.15 \\
\hline $\mathrm{r}^{*}$ & $\begin{array}{l}\text { optimal route spacing for } \\
\text { conventional bus(mile) }\end{array}$ & 0.84 & 0.73 \\
\hline M & $\begin{array}{l}\text { equivalent average user trip distance } \\
\text { for conventional bus (mile) }\end{array}$ & 3.39 & 3.39 \\
\hline$F_{t}^{*}$ & taxi fleet size (vehicle) & 74 & 47 \\
\hline$C_{f}$ & flexible bus service cost (\$/trip) & 3.69 & 3.01 \\
\hline$C_{p}$ & private vehicle cost (\$/trip) & 4.71 & 3.00 \\
\hline$C_{t}$ & taxi service cost (\$/trip) & 5.79 & 4.44 \\
\hline$C_{c}$ & conventional bus cost (\$/trip) & 4.02 & 2.69 \\
\hline
\end{tabular}

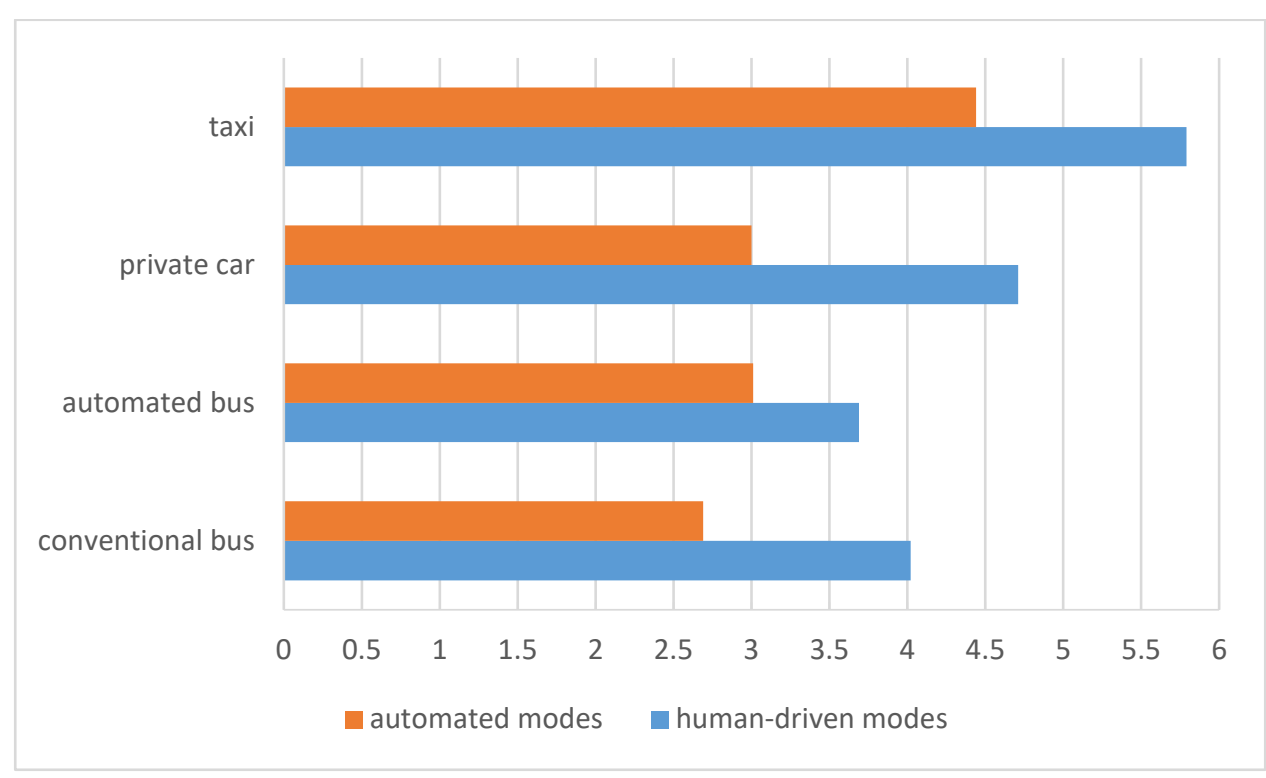

Figure 2 Cost comparison of different modes with and without autonomous vehicle technology

From Table 2 and Figure 2, the following should be noted,

- For bus modes with the assumed cost parameters with fixed demand,

whether fixed route or flexible route, the modes with automation have 
lower costs. This result may be explained by removal of driver cost in automated service for buses and increase in average bus speed.

- The area of service zone of flexible-route bus service tends to increase when automated service is introduced, due partly to the higher speed of AV's, which allows them to cover a larger area in a given time. Another contributing factor is the decrease in value of time caused by the introduction of AV's, which allows passengers to accept longer travel time. A longer travel time and a higher average travel speed allows for a longer travel distance, letting flexible bus to cover a larger service area.

- The optimized bus size for conventional buses tends to be smaller for automated buses than human-driven buses. On the contrary, the optimized bus size for flexible buses tends to be larger for automated buses than human-driven buses. This result may be explained by the relatively faster speed of AV's, as higher road capacity can be obtained with the introduction of AV. Faster buses can carry more passengers per hour, so that the flexible bus can carry more passenger in one round trip. Also, a longer round trip can cover a larger service area, which requires the flexible bus to have a larger bus to provide the service.

- Under the assumed parameter, the fleet size of taxis decreases sharply as automated taxis are introduced. This result may be explained by the 
relatively faster speed of AV's. When the demand is fixed, automated taxi can provide the same level of service with a smaller fleet.

\subsection{Formulation of Utility Functions}

In this section, the relative competitivity of each transportation mode are quantified to exam which mode is preferable under baseline value. A simple multinomial logit model is applied to determine the probability that each mode is selected.

The random utility of alternative $i, U_{i}$, for an individual in random utility models take the form

$$
U_{i}=V_{i}+\varepsilon_{i}
$$

where $V_{i}$ is the systematic component of the utility of alternative $i$ which is a function of observed attributes of alternative $i$, and $\varepsilon_{i}$ is the random component of the utility function. For simplicity, the random component is ignored. The systematic component $V_{i}$ in this case is the user cost and price. The coefficients for user cost and price are assumed to be 1.0. Thus, the utility function for these eight transportation modes can be described as

$$
\mathrm{U}=-C_{\text {user }}-\text { Price }
$$

The author follows Bösch et al. (2018) in reformulating price as follows:

$$
\text { Price }=\frac{C_{\text {supplier }}}{(1-\alpha)(1-\beta)}(1+V A T)
$$

where $\alpha$ is expected profit margin, $\beta$ is payment transaction fee, VAT is value-added tax.

The probability of choosing one of eight transportation modes can be formulated as 


$$
P(\text { choice }=i)=\frac{\exp \left(U_{i}\right)}{\sum_{i=1}^{8} \exp \left(U_{i}\right)}
$$

Then, the utilities using baseline value acquired from Table 1 are evaluated.

The utility with $100 \%$ market share for each mode under baseline value can be found in Table 3.

Table 3 Utility for each mode

\begin{tabular}{lr}
\hline modes & utility \\
\hline human-driven conventional bus & -6.224 \\
automated conventional bus & -3.618 \\
human-driven flexible bus & -3.425 \\
automated flexible bus & -3.167 \\
human-driven private car & -4.627 \\
automated private car & -2.794 \\
human-driven taxi & -6.369 \\
automated taxi & -5.439 \\
\hline
\end{tabular}

Using logit model to predict the market share, at first, the market shares are as follows.

Table 4 Mode share for first iteration

\begin{tabular}{lr}
\hline modes & \multicolumn{1}{c}{ share } \\
\hline human-driven conventional bus & $1.10 \%$ \\
automated conventional bus & $14.86 \%$ \\
human-driven flexible bus & $18.03 \%$ \\
automated flexible bus & $23.33 \%$ \\
human-driven private car & $5.42 \%$ \\
automated private car & $33.91 \%$ \\
human-driven taxi & $0.95 \%$ \\
automated taxi & $2.40 \%$ \\
\hline
\end{tabular}

Using the mode share of each transportation mode generated from the first mode selection as the input demand of next iteration. After 20 iterations, the market shares are,Table 5 Mode shares at 20th iteration

\begin{tabular}{ll}
\hline modes & share \\
\hline human-driven conventional bus & $0.00 \%$
\end{tabular}




\begin{tabular}{lr} 
automated conventional bus & $0.00 \%$ \\
human-driven flexible bus & $0.00 \%$ \\
automated flexible bus & $31.32 \%$ \\
human-driven private car & $6.32 \%$ \\
automated private car & $62.36 \%$ \\
human-driven taxi & $0.00 \%$ \\
automated taxi & $0.00 \%$ \\
\hline
\end{tabular}

As Tables 4 and 5 show, automated private car has the highest market share under baseline values. After ten iterations, the market shares of most human-driven modes decrease to zero except for the human-driven private car, and the mode with greatest market share is still automated private car. The main reason for decrease in human-driven mode is that when travel demand decreases, the unit cost per trip keeps increasing as driver cost remains the same, hence the driver cost becomes a much more significant part of total cost. For example, the proportion of driver cost for $\mathrm{HC}$ increase from $30.3 \%$ to $96.5 \%$. The reasons why market shares of conventional buses decrease to zero are also due to the decrease in travel demand. Conventional bus service carries more passengers per trip, allowing the cost of conventional buses to be lower when travel demand increases. The increases in market shares of private vehicles after twenty iterations are because the formulations of cost for private vehicles are irrelevant to demand density. In summary, from Table 4 and 5, the introduction of automated vehicles might greatly change the relative competitiveness of transit modes. As for public transit, conventional bus transit, whether automated or human-driven, might be eliminated as automated flexible buses can satisfy most public travel demand. Also, private vehicles might play a more important role in urban transportation after automated vehicles are introduced. One thing should be noticed is that the formulation of cost of private mode does not consider the cost of 
owning the vehicle, allowing the relative competitiveness of private modes to be higher. 


\section{Chapter 5: Sensitivity Analysis}

Sensitivity analyses are conducted to explore the relative merits of all eight transportation services in different circumstances. Five cases are presented below. For sensitivity analysis, only one parameter at a time is changed while others are maintained at their baseline values.

\subsection{Demand Density}

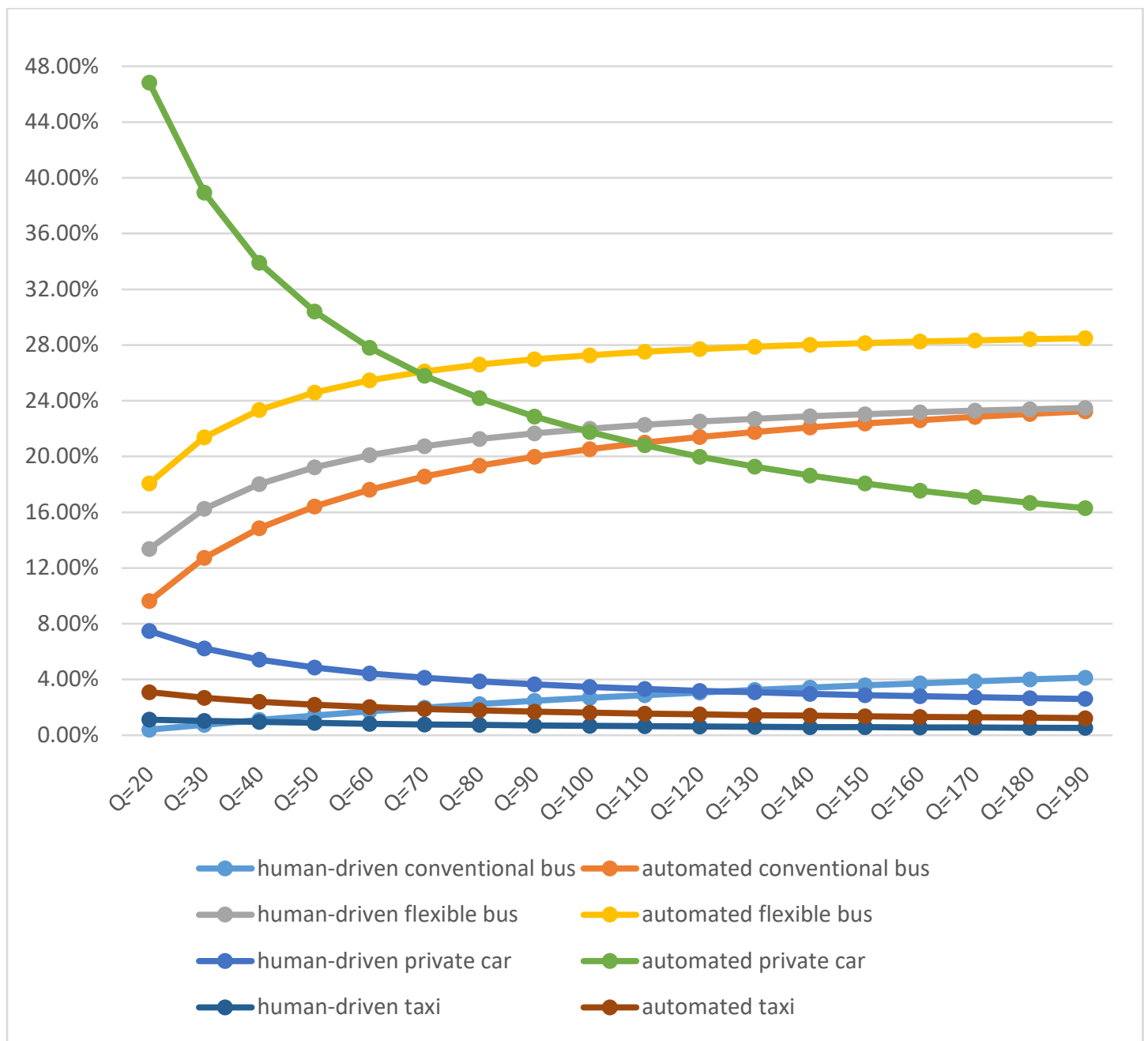


Figure 3 Sensitivity analysis: demand density and market share

- Figure 3 shows that as the density $\mathbf{Q}$ increases from $20 \mathrm{trips} / \mathrm{mile}^{2} / \mathrm{h}$ to 190 trips $/ \mathrm{mile}^{2} / \mathrm{h}$, the market share for all four bus modes increases, first sharply, then at a decreasing rate. The reason why cost of bus modes decrease as demand density increase is because its economy of having more passengers in one vehicle. The costs of private modes remain the same since their speeds are not affected by demand density, which leads to the market share goes down as the cost of other modes decrease.

- Moreover, the automated modes are better than human-driven modes in total market shares, but the gap tends to narrow as $\mathbf{Q}$ increases. As demand density increase, the bus size increases to satisfy the growing demand, allowing one driver to be responsible for more passengers. Thus, the proportion of driver cost decreases as demand increase, leading to narrowing the gap between automation and human-driven modes.

- Regarding bus transit mode, the market shares of conventional bus are increasing faster than flexible bus, which indicates that in areas with higher demand density, fixed-route bus is preferable. When $\mathbf{Q}$ ranges from zero to $70 \mathrm{trips} / \mathrm{mile}^{2} / \mathrm{h}$, the AP is the least costly option. When $\mathbf{Q}$ exceeds 70 , AF becomes preferable.

- Another important finding observable from Figure 3 is how the relative competitiveness of each mode changes when AV's appear. In terms of public versus private transportation, when there are no AV's, 
the results show that bus transit services are more preferable than private vehicles for the assumed baseline parameters. However, when AV's are introduced, the relative competitiveness changes. When Q ranges from zero to 70 trips $/ \mathrm{mile}^{2} / \mathrm{h}$, the AP is the least costly option. This result indicates that when AV's are introduced, the competitiveness of public transit may decrease.

\section{$\underline{5.2}$ Market Penetration of Automated Vehicles}

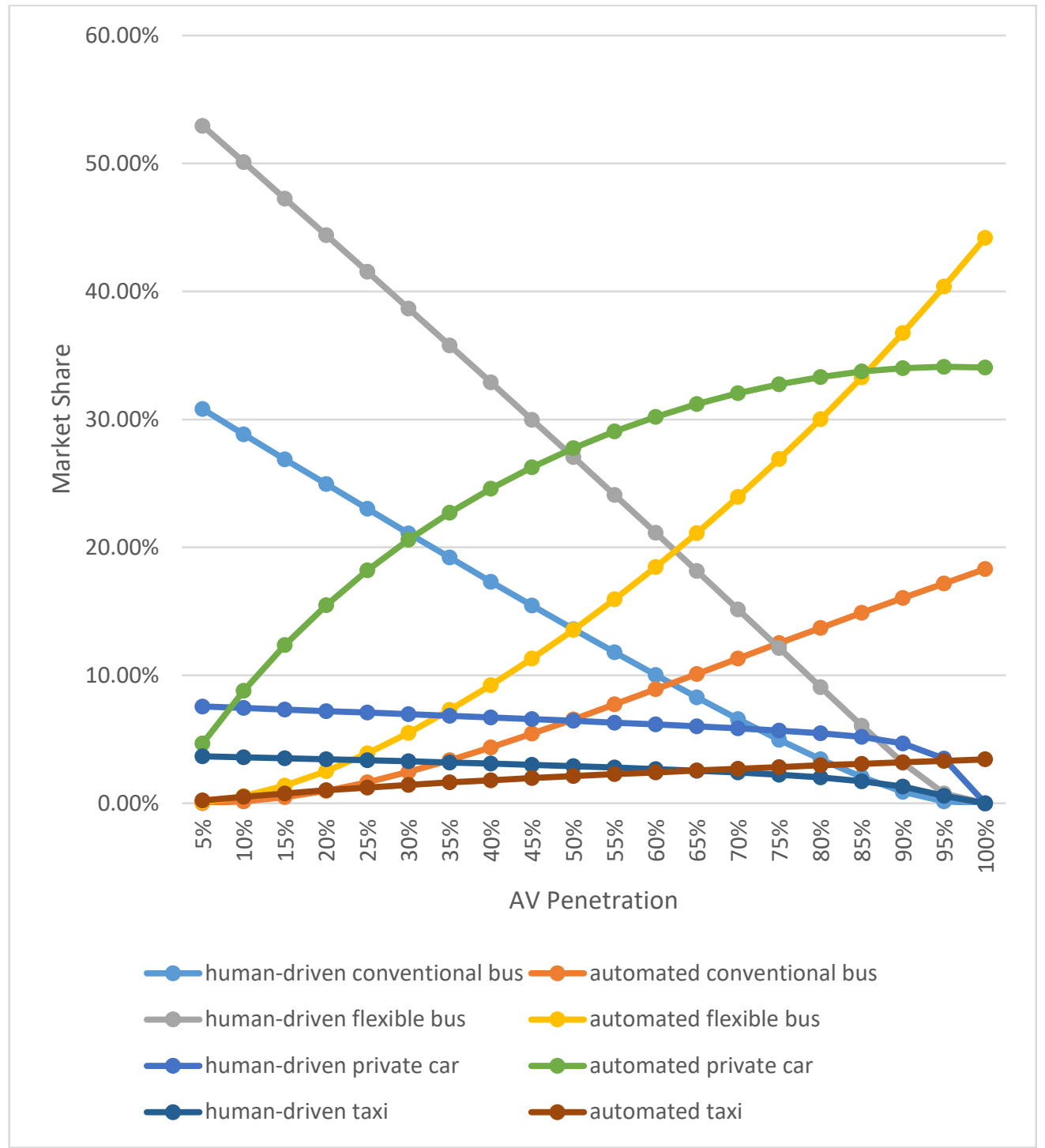


Figure 4 Sensitivity analysis: AV Penetration and market share

- AV market penetration is expected to have a dramatic impact on road capacity and may thus affect the relative performance of each mode. The eight alternatives proposed are assumed to be the only possible vehicle types on the road. Figure 4 shows that the relative competitiveness between $\mathrm{HV}$ change dramatically as AV penetration rises. When $\mathrm{AV}$ penetration is below $70 \%, \mathrm{HC}$ and $\mathrm{HF}$ are the preferable alternatives. When $\mathrm{AV}$ penetration reaches $70 \%$, the market share for HP exceeds HC, indicating as the AV penetration increase, even human-driven conventional bus becomes less cost-effective.

- For $\mathrm{AV}$, when the penetration is greater than $85 \%, \mathrm{AF}$ becomes the most cost-effective alternative. This result can be explained by the increasing AV penetration leads to increasing travel speed, hence flexible bus can carry more passenger in unit time.

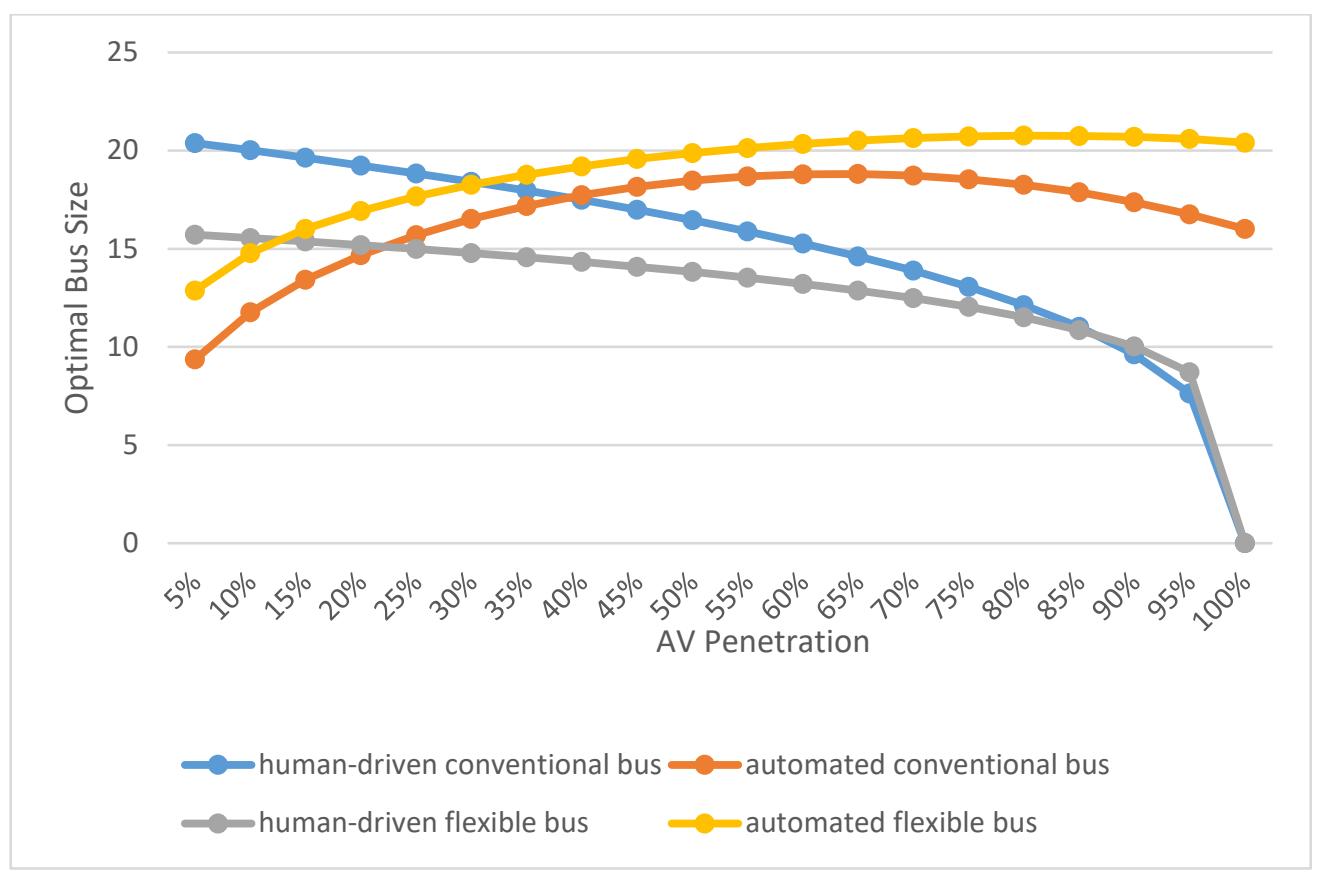


Figure 5 Sensitivity analysis: AV Penetration and optimal bus size

- Figure 5 shows the sensitivity of optimal bus size for $\mathrm{AC}, \mathrm{HC}, \mathrm{AF}$ and HF. It shows that the sizes of both $\mathrm{AC}$ and $\mathrm{AF}$ first increase, then decrease as the $\mathrm{AV}$ penetration rise. The increase can be explained by the raise in $\mathrm{AV}$ penetration, hence the demand for $\mathrm{AC}$ and $\mathrm{AF}$ increase. The decrease indicates that with AV, smaller buses are preferable. This occurs because the increase in $\mathrm{AV}$ penetration leads to the increase in average travel speed, allowing buses to cover more round-trips per time period. Thus, the bus headway decreases, and smaller buses can satisfy the demand.

- Moreover, the AC size decreases faster than the AF size with the rise of $\mathrm{AV}$ penetration. This occurs because when there are no $\mathrm{AV}$, the economy of having more passengers per paid driver is the merit of conventional bus. As AV penetration increase, the elimination of driver cost reduces the need for having more passengers in a bus, which favors smaller buses for AC. 


\subsection{Cost of Driver}

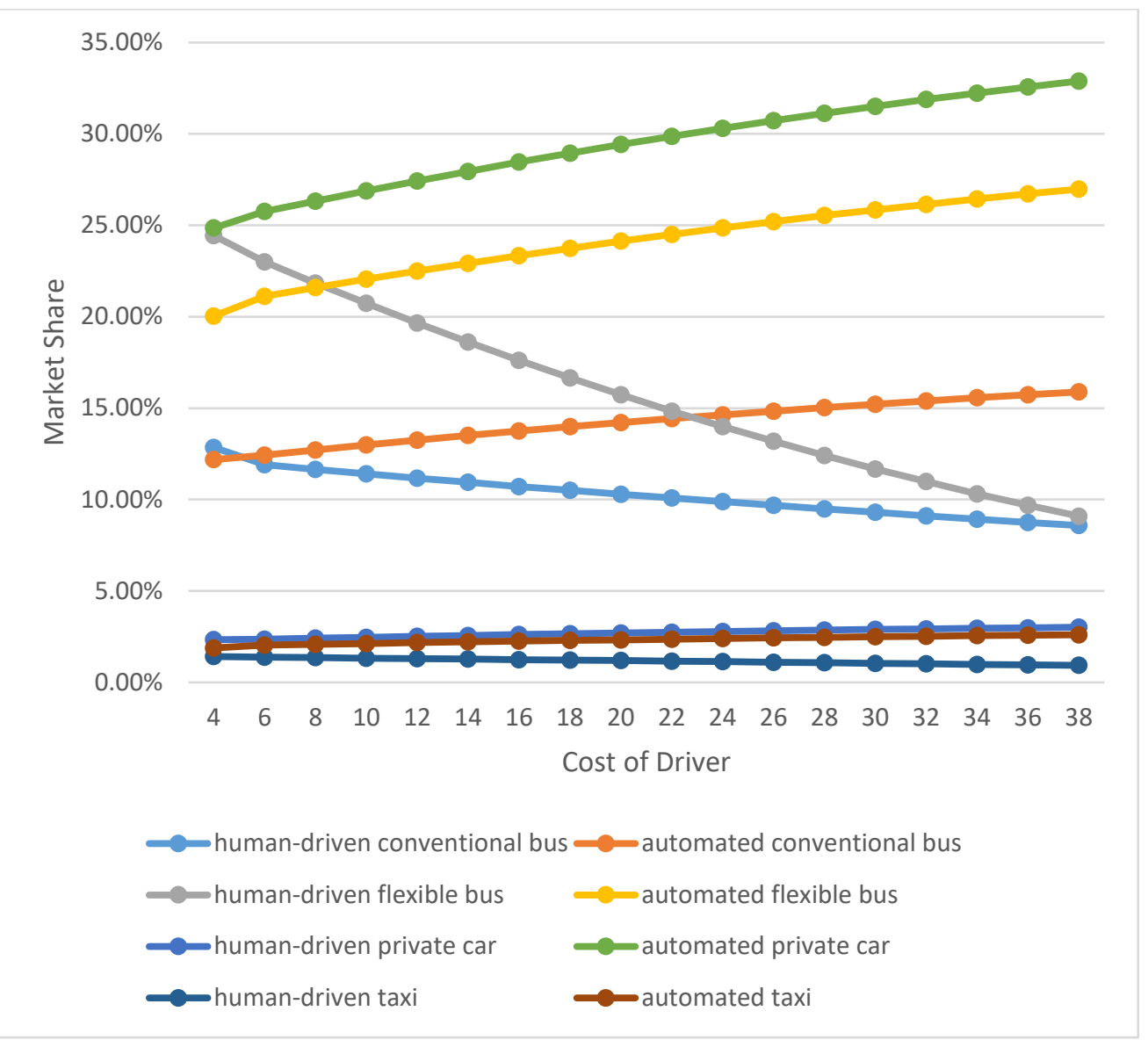

Figure 6 Sensitivity analysis: Cost of driver and market share

- Figure 6 shows the sensitivity of market share of each alternative with respect to the driver cost. Figure 6 indicates that when driver cost exceeds 8 \$hour, the AF's market share exceeds the market share of $\mathrm{HF}$ under baseline value. Also, for the assumed parameters, the AP is always the most preferable mode, as it eliminates the driver cost while benefitting from the higher speed of AV.

- It can be noted from Figure 6 that without AV's, using bus transit is much preferable to using private car despite the high driver cost. This result can be explained by the economies of having many passengers 
in a bus. However, the relative competitiveness changes as AV's are introduced. This result also suggests that when AV's are introduced, private modes may become more competitive.

\subsection{Automation Parameters}

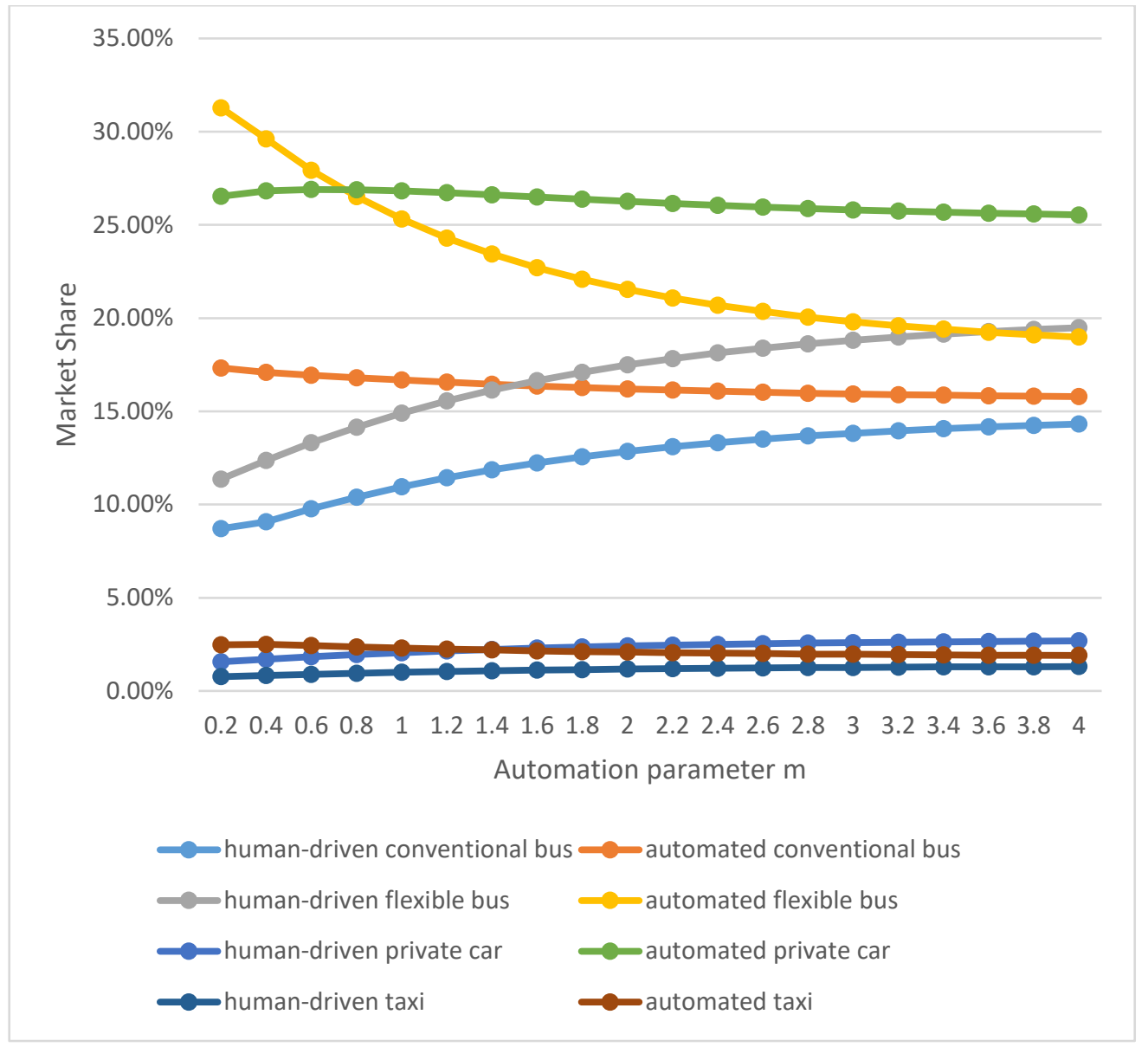

Figure 7 Sensitivity analysis: automation parameter and market share

How relative competitiveness of each mode can be affected by the change in value of time reduction parameter $\boldsymbol{\theta}$ and parameter for capacity function $\boldsymbol{m}$ is evaluated in this section. This sensitivity analysis explores the effects of the shape of capacity function by varying the power $\mathrm{m}$, of the polynomial in Equation2: 


$$
r[f]=1-0.5 \cdot f^{m}
$$

For a power of $m=0$, there is a constant capacity effect that is independent of f. For $m \geq 1$, the higher $m$ is, the more convex the capacity function. Our base case has $\mathrm{m}=2.0$ and thus the capacity function is highly convex with respect to $\mathrm{AV}$ market penetration. As shown in Figure 7, as the power of $m$ increases, the market share for each AV mode increases. This occurs because when $\mathrm{m}$ increases, the gain in road capacity for AV decreases, which further leads to decreasing travel speed and, accordingly, increasing total cost. Thus, the shape of the capacity function can greatly affect the total cost of each mode. 


\section{$\underline{5.5}$ Line-haul Distance}

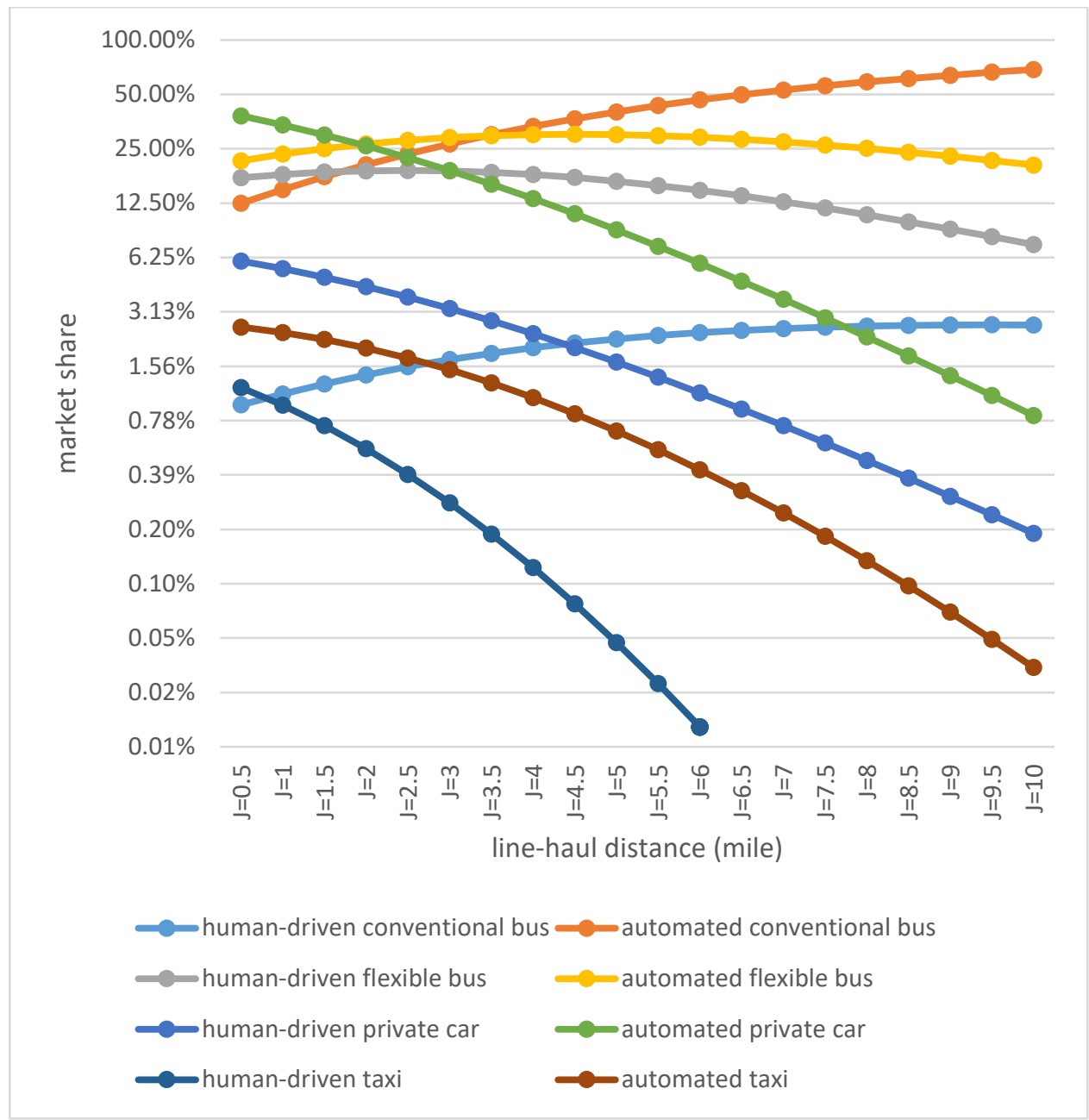

Figure 8 Sensitivity analysis: line-haul distance and market share

- Figure 8 shows the sensitivity of market share of each alternative with respect to the line-haul distance. One thing should be noticed is that the vertical axis is not evenly displayed, as the market shares of some transportation modes are too small to be shown in one figure. Also, the market shares of human-driven taxis when line-haul distance is greater than 6 miles are neglected as these market shares are too small. As 
shown in Figure 8, line-haul distance can greatly affect the relative competitiveness of each transportation mode.

- First, when line-haul distance increases, the market shares of HP, AP, HT, AT decrease dramatically, indicating that vehicle with small capacity can be less competitive. These decreases can be explained by the lack of economy of having many passengers in one vehicle compared to bus services. On the contrary, the only two modes with steady increase are $\mathrm{AC}$ and $\mathrm{HC}$, indicating that conventional bus services are better received when line-haul distance grows.

- Secondly, automated conventional bus becomes the mode with highest market share when line-haul distance exceeds 3.5 miles, as it enjoys the economy of the buses and the higher speed of automated vehicle.

- Thirdly, it can be noted from Figure 8 that when line-haul distance rises, the competitiveness of bus modes greatly increases, regardless of human-driven or automation. Meanwhile, the increases in automated modes are much greater then increases modes. This indicates that automated modes are more competitive in area with longer line-haul distance. 


\subsection{Expected Profit Margin Parameter}

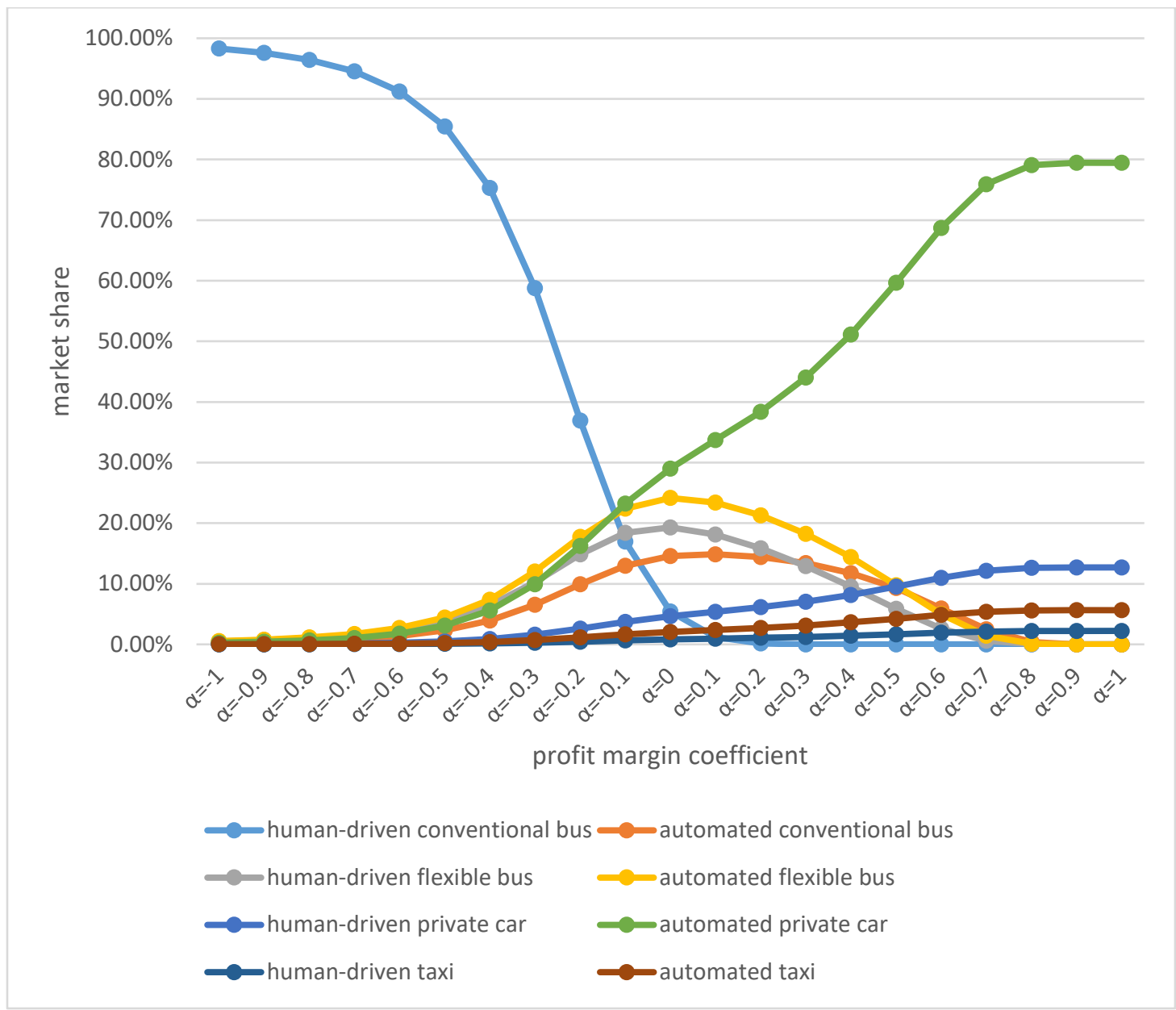

Figure 9 Sensitivity analysis: profit margin coefficient for bus and market share

- Figure 9 shows the sensitivity of market share of each alternative with respect to the profit margin coefficient for bus $\alpha$ ranging from -1.0 to 1.0. $\alpha=-1$ indicating that the bus services are fully subsidized while $\alpha=1$ means that the profit reaches twice of the cost. As shown in Figure $9, \alpha$ can greatly affect the relative competitiveness of each transportation mode.

- As shown in Figure 9, when $\alpha$ increases, apparently the market shares of HP, AP, HT, AT increase dramatically as the increase of $\alpha$ leads to 
the increase of price for bus services, allowing private modes and taxi services enjoy a relatively lower cost, resulting the increase of their market shares. On the contrary, the market share of human-driven conventional bus decreases drastically as $\alpha$ rises, indicating that its high market share when $\alpha$ is relatively low relies more on subsidy. Meanwhile, the market shares of AF, HF, AC first rise as the cost of $\mathrm{HC}$ increase, then decrease because of the increase in price.

- Secondly, automated private becomes the mode with highest market share when $\alpha$ exceeds -0.1 , as it doesn't have to make profit and enjoys the higher speed of automated vehicle.

\section{$\underline{5.7} \underline{\text { Load Factor }}$}

Table 6 Sensitivity analysis: optimized parameter with respect to load factor

\begin{tabular}{|c|c|c|c|c|}
\hline variable & $\begin{array}{l}\text { baseline value } \\
\text { (human-driven) }\end{array}$ & $\begin{array}{l}\text { baseline value } \\
\text { (human-driven) } \\
\text { load factor }=1.25\end{array}$ & $\begin{array}{l}\text { baseline value } \\
\text { (automated) }\end{array}$ & $\begin{array}{l}\text { baseline value } \\
\text { (automated) load } \\
\text { factor }=1.25\end{array}$ \\
\hline $\mathrm{S}^{*}$ (flexible) & 15.88 & 12.7794 & 20.42 & 18.5435 \\
\hline $\mathrm{A}^{*}$ & 2.91 & 2.9371 & 4.14 & 3.142 \\
\hline $\mathrm{Y}$ & 29.97 & 34.0786 & 33.26 & 35.5846 \\
\hline $\mathrm{S}^{*}($ fix route $)$ & 22.34 & 16.5875 & 17.26 & 18.6155 \\
\hline $\mathrm{h}^{*}($ flexible $)$ & 0.14 & 0.18 & 0.12 & 0.1907 \\
\hline $\mathrm{h} *($ fix route $)$ & 0.17 & 0.136 & 0.15 & 0.1844 \\
\hline $\mathrm{r}^{*}$ & 0.84 & 0.72 & 0.73 & 0.7627 \\
\hline M & 3.39 & 3.39 & 3.39 & 3.39 \\
\hline$F_{t}^{*}$ & 77 & 77 & 47 & 47 \\
\hline$C_{f}$ & 3.69 & 3.0668 & 3.01 & 2.8265 \\
\hline$C_{p}$ & 4.71 & 4.71 & 3 & 3 \\
\hline$C_{t}$ & 5.79 & 5.79 & 4.44 & 4.44 \\
\hline$C_{c}$ & 4.02 & 3.6056 & 2.69 & 3.3763 \\
\hline
\end{tabular}

In this case, maximum load factors for all bus service are increased from 1 to 1.25 (implying that some standees are allowed). Table 6 shows the resulting costs and 
other variables. It is noted that only the costs of automated conventional service are above the baseline case. Other types of service regardless of conventional or flexible route bus service benefit from higher load factors. However, the effect of automated service is saving about $18.43 \%$ and $33.08 \%$ for conventional and flexible bus with load factor of one respectively, saving only $7.84 \%$ and $6.36 \%$ for bus with load factor of 1.25, indicating the increase in load factor can reduce the benefit from automation, but increase the competitiveness of bus services. 


\section{Chapter 6: Conclusions and Future Studies}

This dissertation analyzes several interesting problems in order to evaluate the impact of automated vehicle to transit systems. Contributions of this research are valuable for bus transit planning purposes. To be implemented realistically, further research is required, as discussed in the future studies section. Findings and contributions of this research are discussed below.

\subsection{Findings and Contributions}

This thesis formulates and applies optimization models to explore the effects of introducing AV's on the relative effectiveness of bus and private car operations. A benchmark model is proposed and then extended into a series of models with various combinations of whether the vehicle is automated and bus route service type. The benchmark model is solved analytically, and the results are shown by numerical study. Sensitivity analyses are comparatively conducted for all proposed modes.

The results from this study should be useful in making investment decisions for transportation infrastructure, especially regarding transit vehicles and facilities, while considering the effects of driverless vehicles. Responsible organizations can evaluate and select appropriate bus transportation modes with the proposed models.

With the reasonable baseline parameter values used here, our quantitative estimations show that AV technology may have positive as well as negative effects on the competitiveness of public transportation. The numerical results suggest that (a) the introduction of AV's can reduce travel cost significantly, which leads to a higher market share for AV modes; (b) bus headway should decrease when AV's are 
introduced; (c) thresholds can be identified to distinguish the demand densities at which the eight proposed modes are most cost-effective. Also, under our baseline values, the results suggest that (d) automated conventional bus service yields the lowest cost per trip; (e) the competitiveness of public transportation compared to private transportation decreases when AV's are included.

\subsection{Limitation of the Study}

There are some limitations in this study. First, in real transit system operations, the elasticity factors of in-vehicle time, waiting time, access time, and fares may be related to the actual transit ridership. Thus, the assumption of a fixed total demand may be revised in further studies. Secondly, if actual ridership data are available, the optimization models presented here may be able to provide more realistic guidance to the transit service planners and managers in what situation transit services are preferable to private services or vice versa. Thirdly, more geographically realistic models, based on Geographic Information Systems (GISs) may also improve the mode selection model. This would be a better guidance for transit planners to choose under what circumstance bus services are preferable to private services.

\subsection{Future Research}

This study can be improved in the following ways:

1. Congestion effects may be considered.

2. Demand variations over time may be modeled.

3. More detailed analysis of parking options and costs seems desirable. 
4. Other public transit modes including rail transit may also be modeled and compared.

5. More realistic demand patterns and network structures may be considered. 


\section{Appendix}

\section{Optimized Fleet Size for Taxi Service}

Set $\left(\frac{\$_{G}^{h}}{L W Q}+\frac{\$_{F}}{L W Q V_{t}^{h}}\right) M=\mathrm{K}$, Equation. 53 can be transformed as

$$
\begin{gathered}
\mathrm{K} F_{t}^{h^{4}}-\frac{2 L W Q M K}{V_{t}^{h}} F_{t}^{h^{3}}+( \\
\left.\left(\left(\frac{L W Q M}{V_{t}^{h}}\right)^{2}-2 L W Q\right) K-1\right) F_{t}^{h^{2}}+\frac{(L W Q)^{2} M K}{V_{t}^{h}} F_{t}^{h} \\
+(L W Q)^{2} K-L W Q=0
\end{gathered}
$$

which can be seen as

$$
A X^{4}+B X^{3}+C X^{2}+D X+E=0
$$

where

$\mathrm{A}=\mathrm{K}, \mathrm{B}=-\frac{2 L W Q M K}{V_{t}^{h}}, \mathrm{C}=\left(\left(\left(\frac{L W Q M}{V_{t}^{h}}\right)^{2}-2 L W Q\right) K-1\right), \mathrm{D}=\frac{(L W Q)^{2} M K}{V_{t}^{h}}, \mathrm{E}=(L W Q)^{2} K-$ $L W Q$.

To solve Equation 66P, Q, R, S, T, and V values must be computed using A, B, C, D, and $\mathrm{E}$.

$$
\begin{gathered}
\mathrm{P}=\frac{B}{4 A}, \quad \mathrm{Q}=\frac{2 C}{3 A} \\
\mathrm{R}=C^{2}-3 B D+12 A E \\
\mathrm{~S}=2 C^{2}-9 B C D+27 A \cdot D^{2}+27 E \cdot B^{2}-72 A C E \\
\mathrm{~T}=-\frac{B^{3}}{A^{3}}+\frac{4 B C}{A^{2}}-\frac{8 D}{A} \\
\mathrm{~V}=\frac{\sqrt[3]{2} R}{3 A \sqrt[3]{S+\sqrt{-4 R^{3}+S^{2}}}}+\frac{\sqrt[3]{S+\sqrt{-4 R^{3}+S^{2}}}}{3 \sqrt[3]{2} A}
\end{gathered}
$$

The roots of the equation can be computed from the value of $\mathrm{P}, \mathrm{Q}, \mathrm{R}, \mathrm{S}, \mathrm{T}$, and $\mathrm{V}$.

$$
\begin{gathered}
\mathrm{X} 1=-\mathrm{P}-\frac{1}{2} \sqrt{4 P^{2}-Q+V}-\frac{1}{2} \sqrt{8 P^{2}-2 Q-V-\frac{T}{4 \sqrt{4 P^{2}-Q+V}}} \\
\mathrm{X} 2=-\mathrm{P}-\frac{1}{2} \sqrt{4 P^{2}-Q+V}+\frac{1}{2} \sqrt{8 P^{2}-2 Q-V-\frac{T}{4 \sqrt{4 P^{2}-Q+V}}} \\
\mathrm{X} 3=-\mathrm{P}+\frac{1}{2} \sqrt{4 P^{2}-Q+V}-\frac{1}{2} \sqrt{8 P^{2}-2 Q-V-\frac{T}{4 \sqrt{4 P^{2}-Q+V}}}
\end{gathered}
$$




$$
\mathrm{X} 4=-\mathrm{P}+\frac{1}{2} \sqrt{4 P^{2}-Q+V}+\frac{1}{2} \sqrt{8 P^{2}-2 Q-V-\frac{T}{4 \sqrt{4 P^{2}-Q+V}}}
$$

$\mathrm{X} 1-\mathrm{X} 4$ correspond to $F_{t}^{h}$, so it can be computed through this method. The only feasible solution satisfying $F_{t}^{h}>0$ is the optimized fleet size $F_{h t}^{o p t}$. The process is the same for automated taxi. 


\section{References}

Bao, J. (2009) "Study on Influencing Factors of Urban Residents Travel Mode Choice." Southeast University, Nanjing, China.

Barnes, G., and Langworthy, P. (2003). “The per-mile costs of operating automobiles and trucks." <http://hdl.handle.net/11299/909> (Jul. 5, 2018).

Chang, S. K., and Schonfeld, P. M. (1991a). "Multiple period optimization of bus transit systems.” Transportation Research Part B: Methodological, 25(6), 453-478.

Chang, S. K., and Schonfeld, P. M. (1991b). “Optimization models for comparing conventional and subscription bus feeder services." Transportation Science, 25(4), 281-298.

Chang, S. K., and Schonfeld, P. M. (1993). "Welfare maximization with financial constraints for bus transit systems.” Transportation Research Record 1395. Transportation Research Board, Washington, DC, 48-57.

Chen, T. D., Kockelman, K. M., and Hanna, J. P. (2016). “Operations of a shared, autonomous, electric vehicle fleet: Implications of vehicle \& charging infrastructure decisions." Transportation Research Part A: Policy and Practice, 94, 243-254.

Chien, S., and Schonfeld, P.M. (1998). "Joint optimization of a rail transit line and its feeder bus system." Journal of advanced transportation, 32(3), 253-284.

Chien, S., and Spasovic, L. N. (2002), “Optimization of Grid Bus Transit Systems with Elastic Demand”, Journal of Advanced Transportation, 36(1), 63-91. 
Childress, S., Nichols, B., Charlton, B., and Coe, S. (2015). "Using an activitybased model to explore the potential impacts of automated vehicles." Transportation Research Record: Journal of the Transportation Research Board, (2493), 99-106.

Del Castillo, J. M., \& Benitez, F. G. (2012). “A methodology for modeling and identifying users satisfaction issues in public transport systems based on users surveys.” Procedia-Social and Behavioral Sciences, 54, 1104-1114.

De Oña, J., De Oña, R., Eboli, L., \& Mazzulla, G. (2013). “Perceived service quality in bus transit service: a structural equation approach.” Transport Policy, 29, 219-226.

Fagnant, D. J., and Kockelman, K. M. (2014). "The travel and environmental implications of shared autonomous vehicles, using agent-based model scenarios." Transportation Research Part C: Emerging Technologies, 40, 1-13.

Fagnant, D. J., and Kockelman, K. M. (2015). "Preparing a nation for autonomous vehicles: opportunities, barriers and policy recommendations." Transportation Research Part A: Policy and Practice, 77, 167-181.

Fagnant, D. J., and Kockelman, K. M. (2018). "Dynamic ride-sharing and fleet sizing for a system of shared autonomous vehicles in Austin, Texas." Transportation, 45(1), 143-158.

Fernandes, P., and Nunes, U. (2012). "Platooning with IVC-enabled autonomous vehicles, Strategies to mitigate communication delays, improve safety and traffic flow." IEEE Transactions on Intelligent Transportation Systems, 13(1), 91-106. 
Freemark, Y. (2015). "Will autonomous cars change the role and value of public transportation." The Transport Politic, 1-9.

Habib, K. M. N., Kattan, L., \& Islam, M. T. (2011). "Model of personal attitudes towards transit service quality." Journal of Advanced Transportation, 45(4), 271-285.

Hoogendoorn, R., van Arerm, B., and Hoogendoom, S. (2014). “Automated driving, traffic flow efficiency, and human factors: Literature review." Transportation Research Record, 2422(1), 113-120.

Imam, M. O. (1998). “Optimal Design of Public Bus Service with Demand Equilibrium", Journal of Transportation Engineering, 124(5), 431-436.

Iseki, H., \& Taylor, B. D. (2010). "Style versus service? An analysis of user perceptions of transit stops and stations.” Journal of Public Transportation, 13(3), 2.

Jansson, J. O. (1980). “A simple bus line model for optimisation of service frequency and bus size.” Journal of Transport Economics and Policy, 14(1), 53-80.

Kamal, M. A. S., Imura, J. I., Hayakawa, T., Ohata, A., and Aihara, K. (2015). “A Vehicle-Intersection Coordination Scheme for Smooth Flows of Traffic Without Using Traffic Lights.” IEEE Transactions on Intelligent Transportation Systems, 16(3), 1136-1147.

Kim, M. and Schonfeld, P. M. (2014). "Integration of Conventional and Flexible Bus Services with Timed Transfers," Transp. Research Part B: Methodological, 68B2, 76-97. 
Kocur, G., and Hendrickson, C. (1982). "Design of local bus service with demand equilibration.” Transportation Science, 16(2), 149-170.

Levin, M. W., and Boyles, S. D. (2016). “A multiclass cell transmission model for shared human and autonomous vehicle roads." Transportation Research Part C: Emerging Technologies, 62, 103-116.

Ma, J. (2006). "Study on Optimization of Space Resources of Urban Road Traffic Facilities.” Southeast University, Nanjing, China.

Milakis, D., Snelder, M., Van Arem, B., Van Wee, G. P., and Homem de Almeida Correia, G. (2015). "Development of automated vehicles in the Netherlands: scenarios for 2030 and 2050." <https://www.bna.nl/wp-content/uploads/2016/02/ Development-of-automated-vehicles-in-the-Netherlands-TU-Delft.pdf $>$ (Jul. 5, 2018).

Mohring, H. (1972). “Optimization and scale economies in urban bus transportation.” The American Economic Review, 62(4), 591-604.

Newell, G. F. (1979). "Some issues relating to the optimal design of bus routes." Transportation Science, 13(1), 20-35.

Ngoduy, D. (2012). “Application of gas-kinetic theory to modelling mixed traffic of manual and ACC vehicles." Transportmetrica, 8(1), 43-60.

Nourbakhsh, S. M., and Ouyang, Y. (2012). "A structured flexible transit system for low demand areas". Transportation Research Part B: Methodological, 46(1), 204216. 
Office of the Secretary. (2017). "Benefit-Cost Analysis Guidance for TIGER and INFRA Applications.” U.S. Department of Transportation.

Shladover, S. E., Su, D., and Lu, X. Y. (2012). "Impacts of cooperative adaptive cruise control on freeway traffic flow." Transportation Research Record: Journal of the Transportation Research Board, 2324(1), 63-70.

Spieser, K., Treleaven, K., Zhang, R., Frazzoli, E., Morton, D., and Pavone, M. (2014). "Toward a systematic approach to the design and evaluation of automated mobility-on-demand systems: A case study in Singapore.” In Road vehicle automation, pp. 229-245. Springer International Publishing, Switzerland.

Stein, D. M. (1978). “An asymptotic, probabilistic analysis of a routing problem.” Mathematics of Operations Research, 3(2), 89-101.

Tientrakool, P., Ho, Y. C., and Maxemchuk, N. F. (2011). "Highway capacity benefits from using vehicle-to-vehicle communication and sensors for collision avoidance.” Proc., 74th Vehicular Technology Conference:VTC Fall, IEEE, San Francisco, 1-5.

Tsai, F.M., Chien, S., and Wei, C.H. (2013). “Joint Optimization of Temporal Headway and Differential Fare for Transit Systems Considering Heterogeneous Demand Elasticity”. Journal of Transportation Engineering, 139(1), 30-39.

Tsao, S. M., and Schonfeld, P. M. (1983). "Optimization of zonal transit service." Journal of Transportation Engineering, 109(2), 257-272. 
Tyrinopoulos, Y., \& Antoniou, C. (2008). "Public transit user satisfaction: Variability and policy implications.” Transport Policy, 15(4), 260-272.

Van Arem, B., Van Driel, C. J., and Visser, R. (2006). "The impact of cooperative adaptive cruise control on traffic-flow characteristics.” IEEE Transactions on Intelligent Transportation Systems, 7(4), 429-436.

Van Den Berg, V. A., and Verhoef, E. T. (2016). “Autonomous cars and dynamic bottleneck congestion: The effects on capacity, value of time and preference heterogeneity." Transportation Research Part B: Methodological, 94, 43-60.

Wirasinghe, S. C., and Ghoneim, N. S. (1981). "Spacing of bus-stops for many to many travel demand." Transportation Science, 15(3), 210-221.

Wu, C., Zhao, G., and Ou, B. (2011). “A fuel economy optimization system with applications in vehicles with human drivers and autonomous vehicles." Transportation Research Part D: Transport and Environment, 16(7), 515-524.

Yong-neng, X., Xu-Hong, L., Yan-Dong, Z., \& Shu-Ming, S. (2005). "Satisfaction rule model of modal selection of going outside for civilians." Comput Commun, 23(4), 54-57.Yap, M. D., Correia, G., and Van Arem, B. (2016). "Preferences of travellers for using automated vehicles as last mile public transport of multimodal train trips.” Transportation Research Part A: Policy and Practice, 94, 1-16.

Zhang, W., Guhathakurta, S., Fang, J., and Zhang, G. (2015). "Exploring the impact of shared autonomous vehicles on urban parking demand: An agent-based simulation approach.” Sustainable Cities and Society, 19, 34-45. 
Zhao, L. (2008). "Study on the Impact of Parking Charge on Travel Mode Choice.” Beijing Jiaotong University, Beijing, China.

Zhou, Y., Kim, H.S., Schonfeld, P., Kim, E. (2008). "Subsidies and Welfare Maximization Tradeoffs in Bus Transit Systems", The Annals of Regional Science, $42,643-660$.

Zwaneveld, P. J., and Van Arem, B. (1997). "Traffic effects of automated vehicle guidance systems, a literature survey." INRO-VVG 1997-17,VI+38P. 